\title{
An ecosystem approach to health and its applications to tropical and emerging diseases
}

\author{
Uma abordagem ecossistêmica à saúde e suas \\ aplicações às doenças tropicais e emergentes
}

\footnotetext{
${ }^{1}$ Department of Population Medicine and Network for Ecosystem Sustainability and Health, University of Guelph. Guelph, Ontario, Canada N1G $2 W 1$
}

\begin{abstract}
Disease and health outcomes occur within a complex socio-ecological context characterized by feedback loops across space and time, self-organization, holarchies, and sudden changes in organization when thresholds are reached. Disease control programs, even if they are successful, may undermine health; conversely, programs in agriculture and economic development designed to improve health may simply alter disease patterns. A research and development strategy to promote sustainable health must therefore incorporate multiple scales, multiple perspectives, and high degrees of uncertainty. The ecosystem approach developed by researchers in the Great Lakes Basin meets these criteria. This has implications for community involvement in research, development policies, and for understanding and controlling tropical and emerging diseases. Even if unsuccessful in achieving specific outcome targets, however, the requirements of this approach for open and democratic communication, negotiation, and ecological awareness make its implementation worthwhile.
\end{abstract}

Key words Ecosystem; Tropical Medicine; Public Health; Health

Resumo As manifestações de doença e de saúde ocorrem em contexto socioecológico complexo, caracterizado tanto por circuitos de retroalimentação, que atravessam o espaço e o tempo, quanto pela auto-organização, holarquias e mudanças bruscas ao nível da organização ao atingir-se certos limiares. Mesmo programas de controle de doenças bem sucedidos podem prejudicar a saúde; inversamente, programas agrícolas e de desenvolvimento econômico projetados para melhorar a saúde podem alterar os perfis das doenças. Assim, uma estratégia de pesquisa e desenvolvimento voltada à promoção sustentável da saúde deve incorporar múltiplas escalas e perspectivas e elevados graus de incerteza. A abordagem ecossistêmica desenvolvida por pesquisadores na Bacia dos Grandes Lagos satisfaz tais critérios, com implicações importantes para a participação comunitária em pesquisa e políticas de desenvolvimento, bem como para a compreensão e controle de doenças tropicais e emergentes. Ainda quando a abordagem ecossistêmica não obtém êxito quanto a metas específicas, exigências de comunicação aberta e democrática, negociação e consciência ecológica justificam sua implementação.

Palavras-chave Ecossistema; Medicina Tropical; Saúde Pública; Saúde 


\section{Introduction}

For several decades after World War II, many parts of the world undertook committed efforts to eradicate diseases through applied biomedical sciences and promote health through public programs fostering social and economic equity. Both efforts seemed to be successful. Then, in the closing years of the twentieth century, the efforts to promote health were largely abandoned in favor of increasing economic activity per se, at the cost of rapidly rising income disparities within and between countries (UNDP, 1999). At the same time, infectious diseases once thought to be all but eradicated have begun to reemerge as serious problems throughout the world (Lederberg et al., 1992; Waltner-Toews, 1995). All of this is occurring in a context of global environmental change occurring at speeds and a scale unprecedented in recent human history. This would appear to be a good time to reconsider how we think about human diseases, health, and their ecological and social contexts.

\section{What is health?}

Good health, according to the preamble of the World Health Organization, is “... a state of complete physical, mental, and social well-being and not merely the absence of disease or infirmity." This is clearly a utopian definition, a heaven-on-earth which humanity may well strive for, but never - except in rare moments perhaps when good wine and good friends conspire together - achieve. Microbiologist Rene Dubos, as an antidote to this utopianism, suggested that good health was simply a " modus vivendi enabling imperfect [people] to achieve a rewarding and not too painful existence while they cope with an imperfect world" (Last, 1988:57). A Dictionary of Epidemiology (Last, 1988:57) also proposes a more pedestrian, but perhaps more workable, definition of health as: "A state characterized by anatomical, physiological, and psychological integrity, ability to perform personally valued family, work, and community roles; ability to deal with physical, biological, psychological, and social stress; a feeling of well-being; and freedom from the risk of disease and untimely death."

In general, definitions of the health of plants, animals, people, communities, and ecosystems include some notion of current balance and harmony and some notion of reserve (WaltnerToews \& Wall, 1997) or capacity to respond and adapt to a changing environment (Constanza et al., 1992). Furthermore, health is directly related to the achievement of desirable and feasible goals, and disease is but one constraint on achieving those goals. Thus the achievement of health is a social activity within biophysical constraints, rather than a biomedical activity within social constraints. Furthermore, those who possess the skills required to prevent and treat disease - analysis, diagnosis, treatment, professional authority - are ill-equipped to promote health. Disease prevention and control programs, in fact, may actually create illhealth. If nothing else, an ecosystem approach to health makes this transparent.

\section{Why do we need approaches to improving or achieving health?}

Despite the disclaimer of health being " not merely the absence of disease" in the WHO definition, nearly all efforts to improve human health in the past century have been aimed at ridding the world of various diseases. Indeed, those accomplishments are so remarkable that one might ask, given the obvious benefits of freedom from smallpox, measles, and polio, why one would even bother to discuss alternatives to disease control. Why not simply throw out our vague and luxurious notions of "complete physical, social, and mental well-being” and simply redefine health as "absence from disease or pathology"? Based on the concept of health as the capacity to achieve culturally defined goals, and on the failures of the biomedical model, I would like to suggest that there are sound practical and theoretical reasons for not doing this.

First, many disease-control programs are no longer effective. The rising tide, globally, of multi-resistant organisms and pesticide-resistant insect vectors is the direct, unintended result of therapies we use to control or eliminate them. One short-term response to these "counter-attacks" is simply more of the same more vaccines, more drugs, more pesticides as has been proposed by the Institute of Medicine in the United States. In some ways, this is like responding to successful guerrilla warfare by proposing bigger conventional armies and weapons. I suggest that it is time to ponder the wisdom of our bio-military metaphors and linear causal thinking, to address the flaws in reasoning and tactics we have employed to date, and to use our much vaunted intelligence as a species to find more creative solutions.

Second, success in programs which manifestly promote health in some dimensions - 
such as improvements in agriculture to address food shortage - have had unintended negative effects on other aspects of health, such as disease. Simple talk of creating "supportive environments for health" is characterized by the optimism of a race horse with blinders. Water management programs have had particularly devastating effects by favoring several tropical diseases. Dams are built to generate electrical power, to control flooding, and to generate wealth (all of which are demonstrably supportive of health). Nevertheless they also expand or create new habitat for flora and fauna which cause disease, and remove sources of natural renewal from farmland (Hunter et al., 1982). In Bangladesh, epidemic Kala azar (leishmaniasis) has occurred in populations living within flood control embankments (Minkin et al., 1996), and malaria epidemics, mad cow disease, and cyclosporiasis have all been associated with aggressive agricultural programs (Waltner-Toews, 1999).

More specifically, this cross-sectoral blindness means that control of some diseases through, say, environmental restructuring, leads to the emergence of other diseases. This is most obvious in foodborne diseases, where the industrialization and centralization, which quite naturally accompanied regulations on canning and pasteurization to control botulism and brucellosis, have resulted in the creation of large ecological niches and associated large-scale epidemics of diseases such as salmonellosis. In North America, policies and practices which encourage a voluminous and cheap supply of food, and which on the one hand serve as a preventive against starvation, tend on the other hand to undercut the economic and ecological sustainability of farmers and to create a whole new array of nutritional and disease problems associated with obesity.

Disease control programs themselves can also undermine health in at least two ways. They can disrupt ecological systems which make health possible. Thus we are faced with the dilemma that DDT is useful in bringing malaria under control, but at the same time endangers the integrity of the interactions among insect pollinators, birds, and food production which make sustainable livelihoods, and health, possible. Secondly, and less obviously, food supplementation, vaccination, and drug treatment programs based on a biomedical model can undermine the ability of people to adapt resourcefully to their own environments. They do this by reinforcing the notion that it is appropriate for outside experts to determine which outcomes - among many possi- ble competing ones - are appropriate, which responses are "correct", and who should carry them out. Physicians and veterinarians who are well equipped to diagnose and treat are in general very poorly trained to promote health, which requires negotiation and adaptation.

Current health and disease control programs often work against each other across organizational scales. Drawing inferences about populations based on studies of individuals is termed the atomistic fallacy, and is widespread and widely tolerated in epidemiological studies. Ironically, the converse fallacy - drawing inferences about individuals from population studies - is vigorously guarded against. What this means is that all efforts are focused on finding individual determinants of disease, and the broad systemic conditions - the very conditions which determine whether or not healthy human communities are sustainable - are largely, by design, ignored. Thus we have the absurdity of governments in some industrialized countries giving away groundwater to private companies, who then wrap it in plastic and sell it back to the original owners of the water (the citizens of the country) under the pretense that this is good for their individual health. Even if the water in the bottle could be demonstrated to be superior to tap water (which it is not) it would still have major negative consequences for population health because of the energy and resources required for manufacture and disposal of the bottles.

Problems are solved at an individual level but become major problems at a regional or global level. Thus, saving children through vaccination without concomitant programs in education, nutrition, agriculture, and sustainable livelihoods undermines the health of whole communities and condemns them to slow and painful death and disintegration (McMichael, 1993). Indeed, the tension between sustainable population health, which requires a certain death and replacement rate, and individual health, for which death is the ultimate negative outcome, has no solution within current biomedical models (Waltner-Toews, 2000). The idea that death and maybe even disease might in some sense be important for sustainable health cannot even be conceptualized in a normal biomedical framework.

Finally, current disciplinary-bound approaches to health, which focus on biomedical and personal behavioral issues, inhibit health researchers and workers from addressing the real causes - which reflect irreducible interactions among economics, politics, and ecosystems. This is addressed more fully in a later 
section of this paper on emerging infectious diseases.

The practical problems, contradictions, and dilemmas that have arisen in our quest for less disease and better human health do not simply reflect lack of investment in public health and scientific infrastructure: sewers, water supplies, laboratories, vaccines. These are all important. However, this dis-investment in the public good, widespread under conditions of globalization, is itself a product of a lack of appreciation of the nature and complexity of the problems we are addressing.

\section{The theoretical basis for a new approach to health}

The world we live in can be described as what Russell Ackoff has called "a mess", that is, "interacting problems or issues that are not easy to appreciate as a whole" (Flood \& Carson, 1993: 11). Furthermore, it is clear that the complexity we see in the world around us is not only a property of the world we are studying, but also a property of the interaction between ourselves and the world. Normal, conventional science assumes an objective, external observer. For public health and ecological issues, where people - researchers and subjects alike - are internal to the subject being studied, this assumption is untenable.

Causal models used by epidemiologists and biomedical researchers tend to be linear: specific disease outcomes are defined and studies are designed to identify determinants of those outcomes. In all but a few rare occasions, epidemiological studies focus on determinants of disease in individuals. Models of disease can rarely accommodate the disease outcome itself as a cause of other outcomes which themselves connect back to the disease, or to other diseases or health measures. For instance, we have tended to assume that if scientists identify smoking as a cause of cancer, or tick bites as the vehicle for infection by a parasite, then the public health and behavioral changes necessary to prevent these diseases will be made post haste by an informed public. Cross-scale interactions between individual health and disease outcomes, agricultural and economic policies, social expectations created and reinforced by advertising and entertainment, cultural habits of scientists and non-scientists, evolutionary ecology, and epidemic diseases are rarely studied.

Based on the problems identified above, any new approach to studying and promoting health must at least encompass multiple ecological, social, and health outcomes, and "not just the absence of disease". These multiple outcomes need to be expressed in a context of a set of interactions, with people inside them, rather than looking at the environment as an external "support" or "threat" to health. Secondly, to be adequate to the new tasks facing us, any new theory and plan of action must account for problems of scale and inter-scalar connections.

Systems theory explicitly addresses the connections between various elements, and thus provides a useful starting point. A system is simply a set of elements which interact with each other within a certain boundary. Many attempts have been made to reduce people, farms, households, or ecosystems to well-defined, machine-like systems which can be simulated mathematically. While such models provide some useful information, those which are the least realistic tend to provide the strongest implications for action, while those that are the most realistic provide understanding but suggest no obvious solution to the problems being studied. Puccia \& Levins (1985) suggest that there are unavoidable trade-offs in systems modeling between generality, realism, and precision. "No model", they state, "can be general, precise, and realistic"(Puccia \& Levins, 1985: 9).

In the face of this intransigence of the mess we are in, some scholars retreat to the details of reductionism, with the assurance that if they are not helping the situation, they may at least be supplying data which might be useful. However, the systems literature itself seems to present us with a kind of post-modern smorgasbord of systems ideas, ranging from chaos and catastrophe to soft, dynamic, complex, and ecosystems. Some authors (Funtowicz \& Ravetz, 1994) argue that the interactions between people and ecosystems reflect an "emergent complexity", which cannot be captured by even our most sophisticated complex systems models. This may be true, and should engender humility into all our actions, but does not provide a very useful guide for action itself.

\section{SOHO systems}

Among the options available in the new systems smorgasbord is a set of ideas which brings together conventional, soft, complex, chaotic, management, participatory, and ecosystems. These ideas, subsumed under an umbrella of "the ecosystem approach", are based on the view that the mess we live in can be usefully 
understood as self-organizing, holarchic, open (SOHO) systems (Kay et al., 1999).

\section{Holarchy}

A SOHO system is characterized by patterns of interaction occurring in nested hierarchies (sometimes called holarchies: Checkland \& Scholes, 1990; Allen \& Hoekstra, 1992). Unlike say, a military hierarchy, in which there is a chain of authority, each unit (holon) in a holarchy is both a whole thing and a part of something larger. For instance, individual people are parts of families, which are parts of neighborhoods or villages, which in turn make up larger communities and so on. This means that an initiative, such as improving public hygiene, taken at any given scale (for instance the neighborhood) has implications for holons of which it is a part (the city) as well as the holons of which it is comprised (individuals and families). The speed of change at one scale (say introduction of genetically engineered crops at a field scale) may disrupt ecological and social systems of which they are a part, and which have coevolved over much longer periods of time, so that the expected benefits (improved nutrition to individuals) may not accrue in the expected way (Giampietro, 1994).

\section{Feedback loops}

The interactions in SOHO systems are can be represented as a mixture of positive and negative feedback loops. For instance, people engage in various economic activities - such as clearing land for agriculture, irrigation, mining, house-building - in order to make money to improve the quality of their lives. Wealth generated by these activities may be used to build better roads, schools, and sewage disposal facilities. People who have more schooling may be better able to solve social and public health problems - at which time they may see that some of the activities which made the schools possible may themselves be identified as problems. Agricultural activities or manufacturing may, for instance, result in greater pollution of the water supply and the environment, heavier stress on energy use, and general deterioration of the ecosystem. Some diseases may be prevented when swamps are drained or damns are built, even as habitats for new ones are created.

\section{Self-organization, attractors, and surprise}

In natural SOHO systems, it appears that, as high quality energy (referred to in the thermo- dynamics literature as exergy) and information are pumped into the system, the feedback loops become organized in such a way as to make more effective use of the entering resources, build more structure, and enhance their own survivability. It is this combination of feedbacks, boundaries, and openness which results in what is called self-organization. Self-organization is necessary for life to occur. All living things - organisms, ecological systems, socioecological systems - must remain both bounded, with a set of internally relatively stable interactions, and open to receiving resources and energy, and dumping waste, if they are to remain alive.

Some elements in any ecosystem are more tightly connected than others, and more essential to their mutual well-being and/or the wellbeing of the system overall. The importance of connections is not determined by sector (agriculture, health, business, social, environmental), but by flows of useful energy, resources, and information related to patterns of self-organization. Thus, activities which enable a community to make more effective and elaborate use of natural resources and information are likely to have a greater impact on the viability of a given population than health care activities.

As already suggested, these feedback loops in SOHO systems tend to organize themselves in certain patterns which are coherent. Systems researchers call this self-organization "attractors". Most ecosystems - because of the energy and resources available to them - seem to have a propensity to fall into a certain limited set of possibilities. Despite advertising claims to the contrary, not everything is possible, and we cannot all become whatever we want. We and the ecosystems and societies we live in are comprised of physical elements which constrain our possibilities. Nevertheless, human intentionality and creativity can push or alter these constraints, which may result in new system states - or just in general disintegration. In the latter case, if life is to continue, some new sets of mutually supportive interactions need to arise. C. S. Holling, drawing on studies of forest fires and spruce-bud worm infections, has described a normal pattern of development in many ecosystems which depends on at least one stage of local disintegration. According to his "lazy-eight" model, these ecosystems follow a path from exploitation of disconnected resources into greater conservation and stored energy, creative destruction with release of biomass (small patches of fires or infestation), reorganization, and then exploitation 
again (Holling, 1986). Farmers follow a very controlled version of this as they plant, husband, harvest, cultivate, and then plant again.

Changes between system states may be quite sudden. Ideas of thresholds and breakpoints are well-known in both the epidemiological and ecological literature (May, 1977; Kay et al., 1999). Disease organisms increase to critical levels at which time the probability of adequate contact increases to the point where the epidemic explodes.

There is good evidence that ecosystems can exist in different steady states, reaching critical points and then suddenly reorganizing, during which time there may be drastic changes in species composition and diseases. Research on ice cores from Greenland has indicated that global temperature changes on the order of 5$16^{\circ} \mathrm{C}$ have occurred over mere decades during global climatic changes in the past (Severinghaus \& Brook, 1999; Taylor, 1999). Such "flips" are attributed to the crossing of temperature thresholds required to keep global ocean currents moving in particular ways. These kinds of threshold effects followed by catastrophic changes between attractors have been demonstrated for a variety of systems, social as well as ecological (Casti, 1994; Kay et al., 1999).

This means that gradualist views of disease changes in relation to climate, for instance, may be a very poor basis on which to base organizational response plans, and hence undermine that part of health which comprises the ability to adapt and respond to stress. On the other hand, these insights may also be used to create health benefits disproportionately large relative to the apparent effort. Putting speed bumps on all city streets, and narrowing them, could within a few years result in cleaner air, less respiratory disease, and healthier people who walk more. Of course this would also result in the loss of income from motor-related activities and a change in the physical structure of the cities and in the structure of the national economy. Paying farmers for managing landscapes sustainably as well as for producing commodities would change the entire structure of rural communities, migration to cities, international trade, patterns of foodborne disease, and global economic power. While the exact outcome in either case could not be predicted, an informed public could at least see the general shape of the system options.

\section{Multiple perspectives}

Because such complex feedback loops have both positive and negative effects, different people will look at the situation (and evaluate it) differently. Where one person sees the excitement of economic activity, another person sees deforestation, where one person sees disease control by draining swamps, another person sees loss of wildlife and clean water provided by the filtering effects of wetlands. Where one person sees disease control through metal roofing, another person sees increased economic and environmental costs and less comfortable houses. This means that, as the scientific description gets better, the problems are not necessarily resolved, only clarified.

One challenge to creating systems descriptions is that of selecting what to put into them and what to leave out. We cannot describe everything about everything! Nor does it seem appropriate for expert scientists (which scientists?) to determine what is important and desirable for everyone else. The scientific, ecological information is important, but not sufficient. For this reason, some researchers have developed the idea of extended peer groups and "post-normal science". In normal science, one's disciplinary peers determine the "success" and "quality" of one's work. If we are talking about sustainable, healthy communities, then clearly there are others who will have something important to contribute. This is especially important given the uncertainty of scientific predictions with regard to complex systems.

Given this complex theoretical base and the uncertainty of our knowledge, how can we do scientific research and science-based development in support of health?

\section{What is the ecosystem approach? The practical implications of thinking in terms of complex systems}

The concept of an "ecosystem" dates back at least to British ecologist Arthur Tansley in 1935, and has undergone various permutations in the decades since then (Bocking, 1994). The ecosystem approach, as described in this paper, is a conceptual and management approach developed and applied by ecologists working with the International Joint Commission of the Great Lakes (Allen et al., 1991). These huge freshwater lakes, which straddle the CanadaUS border, are ringed with some of the biggest industrial cities in North America, such as Chicago, Cleveland, Hamilton, and Toronto. In this situation, standard approaches to environmental management, which were designed for smaller areas or parks not usually inhabited by people, did not seem appropriate. 
Combining insights from ecosystem ecology, complex systems theory, catastrophe theory, and hierarchy theory, ecosystem researchers and managers developed a process that anticipates change (without predicting its exact timing and nature) and creates adaptive solutions in a participatory manner. The process itself grew largely out of the work of Peter Checkland, a systems scientist and specialist in business management (Checkland \& Scholes, 1990). Arguing that human activity systems could not be understood or managed like machines, he developed a seven-step "Soft Systems Methodology" which focused on how to understand the goals, perceptions, and transformative actions of people in organizations. This methodology is best worked out for organizations which have definable goals. Allan \& Hoekstra (1992), among others, have explored how to combine such a methodology with the insights gained from natural sciences and ecology. Still others, such as James Kay and members of the "Dirk Gently Group" (The Dirk Gently Group is an informal network of researchers into the problems of decision-making under conditions of complexity and uncertainty. Membership varies, but includes Silvio Funtowicz, Gilberto Gallopin, Mario Giampietro, James Kay, Bruna De Marchi, Tamsyn Murray, Martin O’Connor, Jerry Ravetz, and David Waltner-Toews) have struggled with the problems of how to accommodate human activity systems, multiple perspectives, and the constraints of ecological and energy networks.

According to the Ecological Committee of the International Joint Commission, in the ecosystem approach "there is not one material ecosystem to which our definitions must conform. Rather, the human actor must accept responsibility for erecting definitions and be prepared to change them when the purpose of the description changes" (Allen et al., 1991:5). Generalizing this understanding to recognize that there are many human actors, with many legitimate perspectives, Kay \& Schneider (1994:38) have argued that using an ecosystem approach means "changing in a fundamental way how we govern ourselves, how we design and operate our decision-making processes and institutions, and how we approach the business of environmental science and management."

Central to an ecosystem approach rooted in complex systems theories, then, is the notion that achieving sustainability requires bringing together a variety of legitimate stakeholders, drawing on a variety of accepted bodies of knowledge, to negotiate a learning path based on a series of conflict resolutions within eco- logical constraints. Continual learning based on free flow of information and mutual respect, and investment in democratic local governance, are keys to success (Funtowicz \& Ravetz, 1994; Roling \& Wagemakers, 1998).

This means that, in the ecosystem approach, the practical, social, and institutional dimensions are of as much concern to researchers as the scientific and scholarly concerns. This can get very complicated very quickly, if we remember that these systems are holarchies. Thus, even if the people in one region can agree on a common plan of action, they will need to pay attention to the larger system of which they are a part. On the one hand, urban neighborhoods may not be able to solve all their water problems without help from city or even national authorities in charge of water distribution systems; on the other hand, if local neighborhoods clean up their streets simply by shipping garbage elsewhere, this may create a much bigger, more concentrated problem than the one we started with. Thus local participatory action, while essential, is always conditional, just as individual freedom in society is conditional on interactions with other "layers" in the holarchy (Waltner-Toews \& Wall, 1997).

Both scientific studies and participatory action research (PAR) are necessary ingredients of an ecosystem approach, and both must be reoriented to a systems understanding of reality. Participatory development without science is just politics; science without participatory development is an academic exercise, and without a systems perspective, neither can be used effectively to promote sustainable development or ecosystem health. There is no single way to visually represent this kind of multi-level, multiple perspective research (nor is it the intent of this paper to describe the details of such an approach). Several models have been proposed. A cube with axes representing scale, perspective, and system goals may be used to classify research and management activities (Figure 1, as adapted from VanLeeuwen et al., 1998). Kay et al. (1999) have proposed a twoarmed schematic which emphasizes the interactions between natural sciences and sociocultural visions (Figure 2). Murray and colleagues (Murray et al., 1999) have proposed a flow diagram, the Adaptive Methodology for Ecosystem Sustainability and Health. This puts the emphasis on process, and may give greater guidance for planning and action (Figure 3 Murray et al., 1999).

However this is represented, biomedical researchers, sociologists, anthropologists, natur- 


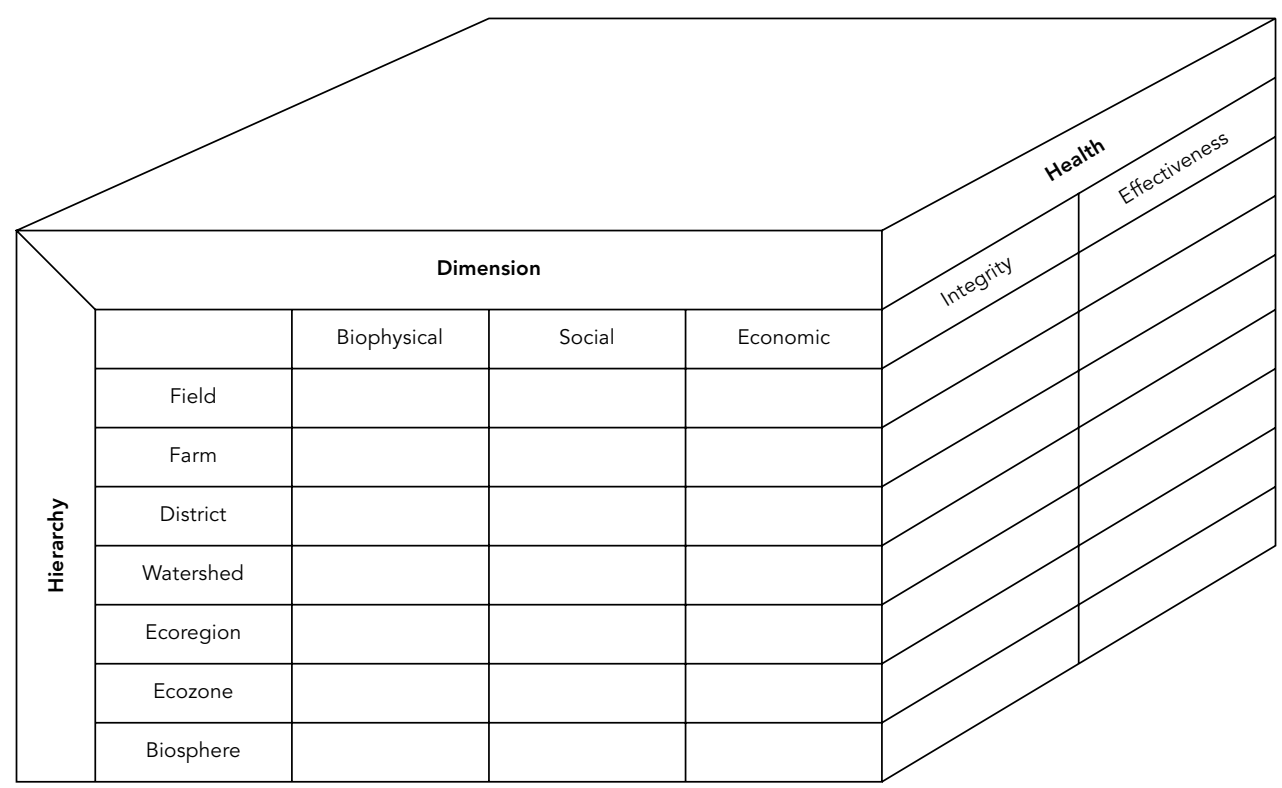

Adapted from Waltner-Toews \& Nielsen, 1995.

al scientists, and ecologists - both professional and lay - must work together to describe the important patterns of natural resource use and dynamics of the ecosystems in which the communities live. At best, what emerges from this collaboration is an evolutionary understanding of how the current system came to be, what the key interactions are which determine its current state, and, based on historical evidence, what kinds of options (attractors) are available. They also describe the system both in terms of the functioning of the diverse flora and fauna that are present, and in terms of their functions for capturing and disseminating useful energy (exergy) (Kay et al., 1999). Finally, the research process itself involves negotiation of goals and implementation of desirable and feasible actions. Within the ecosystem approach, policies, programs, and actions serve the same function as hypotheses and experiments in laboratory science.

Where does disease fit into this? One might begin by re-thinking disease classification in terms of ecological contexts, rather than simply using Linnean classifications. For example, Mara \& Alabaster (1995) have devised an environmental classification of housing-related diseases in developing countries. It is another step in this process to identify how changing housing types might modify the evolution of virulence in malarial parasites. Ewald (1994), among others, has discussed how enclosed housing, which removes prostrate victims of malaria from the pool on which mosquitoes feed, will likely lead to an evolution of malaria to more benign forms. It is also known that metal roofing provides less habitat for Chagas disease vectors; nevertheless, such roofing carries with it ecological costs (use of materials and energy) as well as economic costs which may outweigh their benefits. These pieces of information must be integrated - bringing disease into a health context - as we work intensively with communities in specific places to create healthy social and ecological systems (Gitau et al., 1996; Murray et al., 1999; Yassi et al., 1999).

Because the ecosystem approach is based on a holarchic view of reality, part of the research is to find ways of creating regional and global economic, health, and environmental policies which facilitate, rather than hinder, this work. Health issues need to be put into a holarchic understanding, so we do not run into 


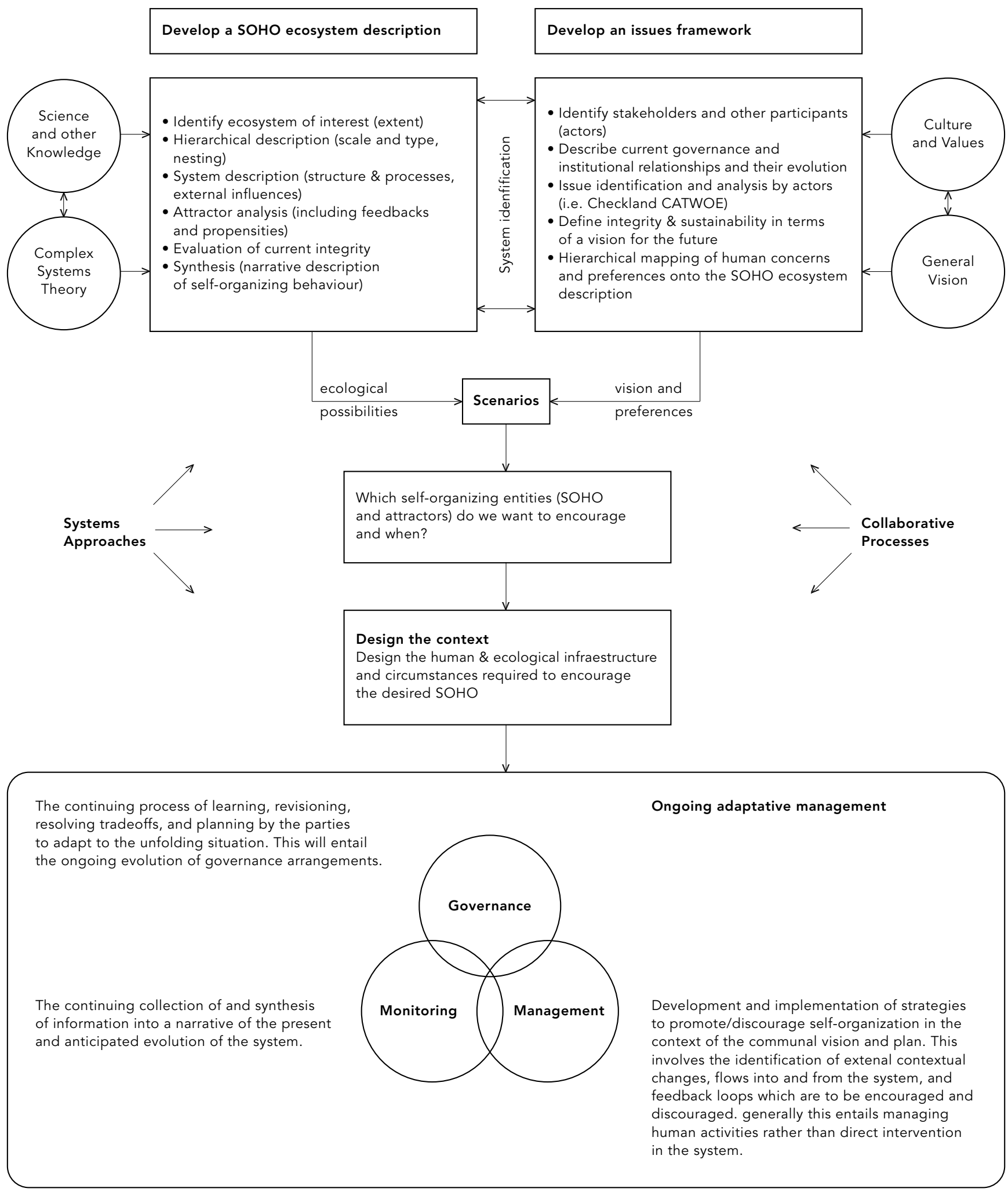


Figure 3

AMESH: the Research Process.

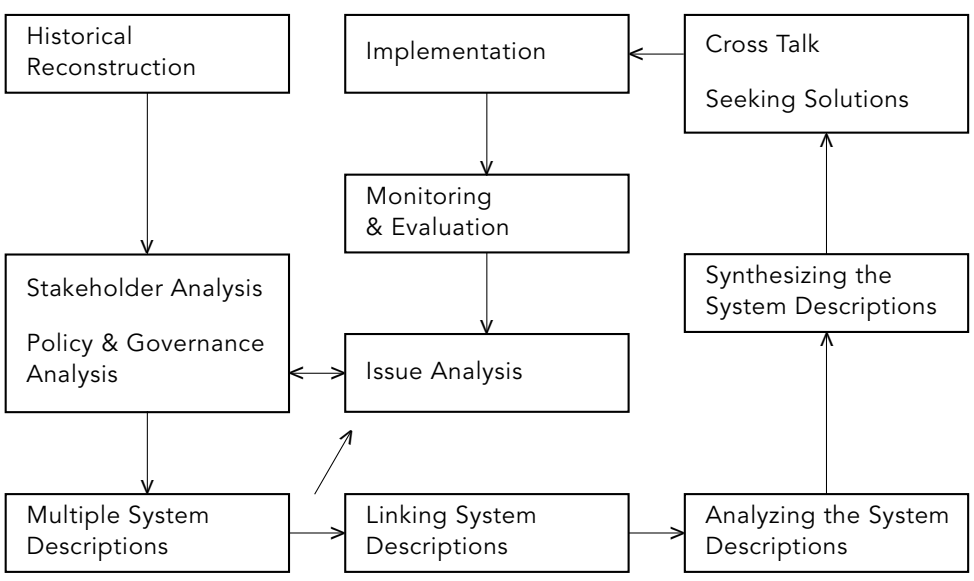

Adapted from Murray et al., 1999) with people to identify goals, to understand the socioeconomic and ecological constraints and opportunities facing them, and to negotiate resolutions rather than "find" solutions, helps those people to become healthy by definition. There is no biomedical solution which can be imposed from the outside to promote health. Thus, an ecosystem approach to health promotes health in the very means it uses to understand and promote health. Secondly, since the ecosystem approach embeds the social goals of health within our best understanding of the ecological context, it is more likely to be sustainable than an approach to health issues which is based on the fantasy of a social reality disconnected from the biosphere.

\section{Implication of the ecosystem approach for research on tropical and emerging diseases}

Emerging, reemerging, and newly recognized diseases in both the tropics and in temperate zones, represent failures - failures to understand the socio-ecological systems we live in, and failures to respond to new understandings as they are uncovered. What we learn from these failures will largely determine how successful we are in creating sustainable and healthy human communities on this planet.

Descriptions of emerging diseases and causes of emergence have been reviewed in several major reports and conferences (Lederberg et al., 1992; Levins et al., 1994; Waltner-Toews, 1995; Meslin, 1997). The Institute of Medicine in the United States, in a 1992 report, identified half a dozen forces which were resulting in the emergence of new diseases and the resurgence of old ones (Table 1 - Lederberg et al., 1992). Peter Drotman of the Centers for Disease Control has pointed out that 150 years earlier, in a report to the Prussian government regarding a typhus epidemic in Upper Silesia, Rudolf Virchow identified causes and made recommendations which are eerily similar to those of the Institute of Medicine (Table 2 - Drotman, 1998). What is clear from both reports - and remarkable given that both men were basic biomedical scientists - is that the causes identified are social, environmental and political. This would come as no surprise to anyone who has done serious research in the area (Evans et al., 1994; Farmer, 1996).

Nevertheless, while Virchow's recommendations are overtly social and political - and hence based on the evidence - those of the IOM seem unconnected with the causes (Table 3). They are at best technical, and at worst 
merely self-serving (at least for biomedical scientists). Where, one might ask, are the recommendations related to some of the root causes they have identified - technology and industry, international trade, investment in public health infrastructure? Based on the evidence presented, should health researchers not be making strong health representations to organizations like the World Trade Organization and the World Bank, not on how to clean up the disease mess after the fact, but on how to prevent the mess in the first place? It would almost appear that the ideological lenses through which emerging diseases - indeed diseases in general - are being studied, preclude acting on the evidence. This, if nothing else, should raise a warning flag that those who study disease are not necessarily well-equipped to promote health, and that new modes of thought are required to promote health at the beginning of the new millennium.

Tropical diseases obviously are related specifically to tropical climate, flora, and fauna. However, if we consider the diseases selected by the World Health Organization's TDR Program (leishmaniasis, onchocerciasis, Chagas disease, leprosy, tuberculosis, African trypanosomiasis, schistosomiasis, dengue, lymphatic filariasis, and malaria), it is also clear that many of these do not simply occur in the tropics because of climate and landscape. Indeed, even the tropical climate is subject to strong influences by the climate-changing behavior of industrialized countries, and landscapes are being transformed by industrialization processes within tropical countries. Diseases such as leprosy and tuberculosis have occurred - and continue to occur - in colder climates where poverty creates homes for them. Even those diseases which are likely constrained by the ecology and climate of the tropics, such as Chagas disease, can clearly be strongly influenced by social and economic practices. Many tropical diseases are thus not only diseases related to climate and environment, but are diseases of poverty. In epidemiological terms, conditions of poverty increase the probability of adequate contact and hence increase the likelihood of epidemics. The disappearance of many infectious diseases - such as cholera, leprosy, tuberculosis, and malaria - has had much more to do with housing, nutrition, and water management than with any advances in biomedical science (Dubos, 1965). This is well established and, I would hope, non-controversial. These public health interventions require public investments. Current drives to evade these requirements by arguing for more re-
Table 1

Factors in emergence of new diseases (Lederberg et al., 1992).

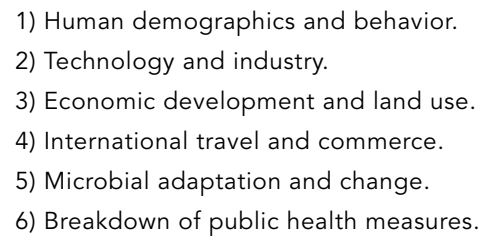

Some of Virchow's recommendations to the Prussian government regarding the typhus epidemic in Upper Silesia, 1848 (adapted from Drotman, 1998).

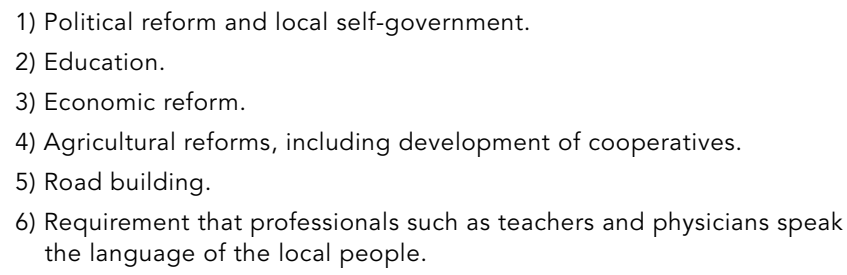

search on drugs and vaccines are largely driven by private enterprise economics and a postCold War fear of seeming to be interested in the public good, rather than on the evidence.

Even if the financial powers could be persuaded to look at the evidence, however, we need to admit that we are working in a different context than that which the Europeans faced at the beginning of the 20th century. The planet is considerably more crowded, northerners are a great deal more insatiable in our consumption of resources, and the whole human enterprise now threatens the ecological integrity of the planet which makes our lives possible (UNDP, 1998). So, on the other end of the political spectrum, we must say that massive public works programs and environmental restructuring of the kind which freed Europeans from infectious disease need to be more carefully considered with regard to their effects on ecosystems (which Virchow did not consider).

The ecosystem approach is a way to bring together the socioeconomic and biophysical dimensions of health. Nevertheless, what it brings to our understanding of emerging diseases is not so much a way of identifying new variables - though it certainly forces us to cast our net much broader than in conventional re- 
1) Development and implementation of more effective State, federal, and global surveillance systems.

2) Expansion of National Institutes of Health (NIH)-supported research on agent biology, pathogenesis, and evolution, vectors and their control, vaccines, and antimicrobial drugs.

3) Generation of stockpiles of selected vaccines.

4) Expedite pesticide registration for vector control and stockpile those pesticides.

5) $\mathrm{NIH}$ give increased priority to research on personal and community health practices relevant to disease transmission and education "to enhance the health-promoting behavior of diverse target groups."

search - but a new way of organizing how we think about them, and how we respond to them. Emerging diseases demonstrate to us how our understanding of nature, and our management responses, have been limited. In particular, our understanding of how social and ecological variables appear to behave as complex adaptive systems changes how we think about social, economic, or environmental management programs. Some of the lessons to be learned have been previously reviewed for foodborne diseases (Waltner-Toews, 1996, 1999) and infectious diseases in general (Levins et al., 1994). This paper will emphasize three particular failures in our understanding and response which have characterized recent discussions on emerging diseases. These failures and insights based on them lead directly into a series of recommendations (Table 4).

1) The failure to understand non-linear interactions, chaotic attractors, and catastrophic thresholds. This failure is apparent in the way in which economic development, agricultural trade policies, and the like are treated, as if they were somehow issues separate from social and mental, as well as physical, well-being. It is also apparent in current gradualist expectations of the consequences of global warming. The promotion of health in an ecosystem context must account for multiple inter-related health outcomes, of which disease reduction is but one. Furthermore, it will focus not so much on linear predictions of health improvement through fixed programs (which appears to be impossible), but on creating adaptive organizational responses.

This leads to my recommendations $1 \mathrm{a}$ and 1b related to system dynamics: 1a) Research should be expanded on the changes in ecosystems which will most likely push them into the domains of new attractors. What, researchers should be asking, are the likely health, environmental, and social effects of such reorganiza- tions? And 1b) That all economic, agriculture, and business policies, approvals of new technologies, and so on be justified in terms of our best understanding of their likely systemic effects, and that they not be undertaken unless those who live in the system agree that those effects are acceptable and/or that we have in place adaptive mechanisms to deal with those changes.

2) The failure to account for holarchy. Current efforts aimed at preventing diseases in individuals are currently undertaken with little thought as to the consequences for population or ecosystem health. Similarly, populationbased programs tend to have a strong autocratic flavor to them which undermines their success.

Failure to account for holarchy has resulted in global trade policies which generate wealth for the global economy, leading to the destruction of local ecosystems and the maintenance of local poverty and infectious diseases (Waltner-Toews, 2000). This is because global and regional policies often destroy local socio-ecological boundaries; individuals whose only loyalty is to the global market undercut the integrity of local social and ecological systems. Of course, healthy individuals, communities, and ecosystems interact with their surroundings and change in response to them. However, globalized commercial trade is just another form of introducing alien and often invasive species into ecosystems; totally free trade is comparable, at the local community and ecosystem level, to pulling the skin off a live animal. Yes, there is more immediate flow of nutrients - but this inevitably leads to local death. Some protectionism is simply an act of survival. Indeed, the very idea of interaction with an environment presupposes the integrity of the boundaries across which the interaction takes place. I must underline, however, that holarchical thinking drives us not to isolationism, nor to globalism, but to interactions with a pro- 
Recommendations to understand and control the emergence of new diseases based on an ecosystem approach to health.

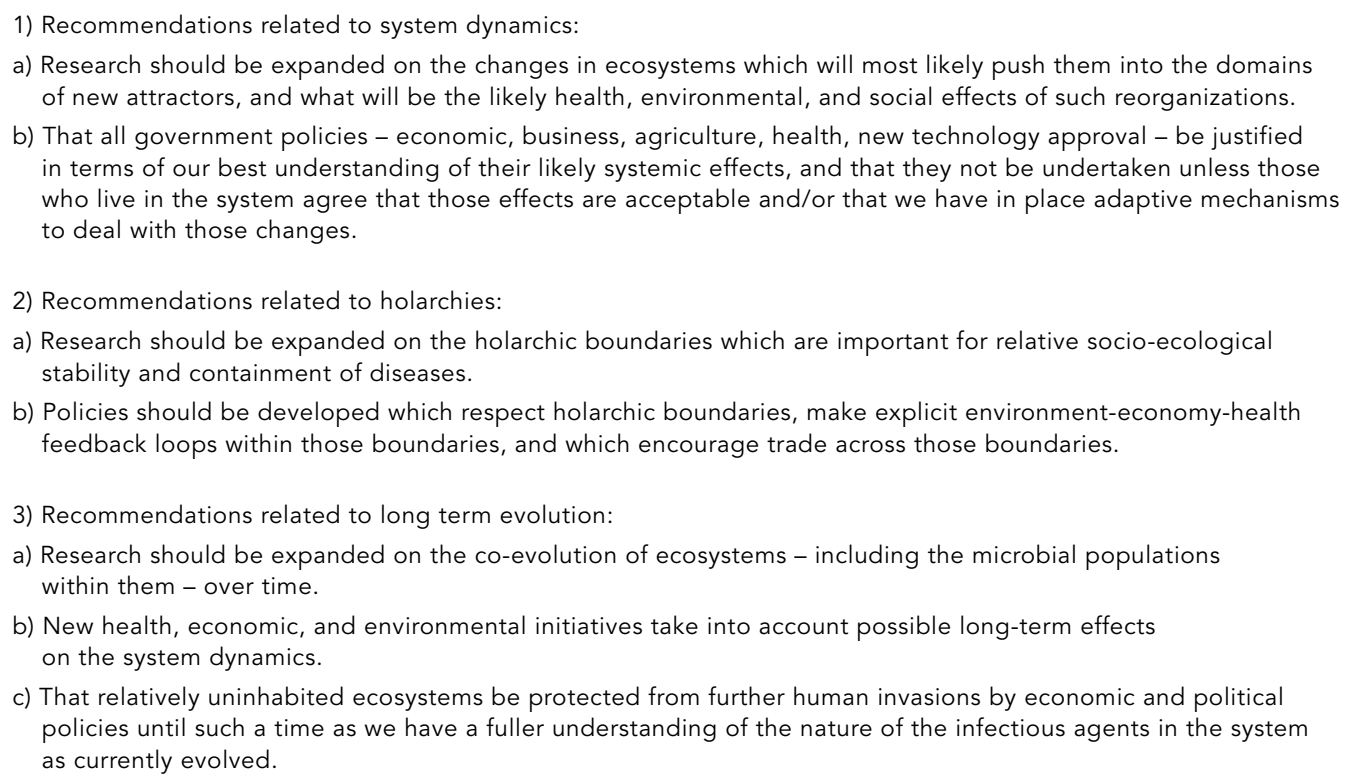

found respect for boundaries and scales. Controlling the emergence of new diseases and creating healthy human communities depend on maintaining the tension within holarchies.

Recommendations $2 \mathrm{a}$ and $2 \mathrm{~b}$ are therefore that 2a) Research be expanded on the holarchic boundaries which are important for relative socio-ecological stability and 2b) Policies be developed which respect holarchic boundaries, make explicit environment-economy-health feedback loops within those boundaries, and which encourage trade across those boundaries.

3) The third failure is one of long-term vision, and hence perhaps the most forgivable. On the one hand, this is the failure to take into account the ecological, evolutionary effects of social and economic programs. The obvious examples are those, like Lyme disease, where reforestation and expanding deer populations, coupled with encouragement of people to enjoy outdoor life, have also had negative disease-emergence effects. But the failure is more widespread than that.

This is also evident when apparently narrowly focused changes are proposed - such as the introduction of new genetic varieties of plants on a wide scale. For instance, the introduction of "green revolution" varieties appears now to have played an important part in the systemic changes which have resulted in more than two billion people worldwide with serious micro-nutrient deficiencies, which may be considered a major non-infectious emerging disease (Welch et al., 1997). Farmers chose new varieties because they grew faster and made them more money. This displaced a variety of other crops and in the process restricted the diet for billions of people. They also became considerably more dependent on fossil fuels (for fertilizers and pesticides), contributing to the mining of non-renewable resources, global warming, and the emergence of new diseases, both infectious and non-infectious. Hence a caloric shortage problem was solved in such a way that the system was reorganized in fundamentally unsustainable ways.

The new wave of genetically modified organisms is being introduced based on the same naïve view of nature that brought in the first wave of introductions, with the probability they will further destabilize ecological systems (Giampietro, 1994). This will no doubt result in changes to micro-flora which will lead to the emergence of new epidemiological patterns of disease. Certainly this is what has already happened with regard to many foodborne illnesses, such as bovine spongiform encephalopathy, antibiotic-resistant Salmonella DT 104, and verotoxin-producing $E$. coli, all of which have emerged in the agrifood system as unintended 
side effects - based on naïve and narrow understandings of social and ecological systems of economic policies intended to promote cheap food. Agricultural and economic development policies can also be held responsible for the (re)emergence of malaria in several parts of the world.

An understanding of possible long-term effects may not lead us to abandon social projects and policies. Indeed, as Ewald and other evolutionary ecologists have pointed out for malaria and cholera, these may be used to good advantage to devise programs to control disease. But these long-term scenarios should at least cause us to build into their structure and implementation mechanisms to detect probably long-term impacts and to compensatory mechanisms for those who are likely to suffer from those changes.

This is not only a failure to see the longterm effects of human social projects, however, but a failure to understand that ecosystems have co-evolved over a long period of time and that when we invade or disrupt those systems, we do so at some peril, not just to the ecosystem (rain forest destruction) but to ourselves, as we become entangled in life cycles that evolved without us, resulting in the emergence of diseases like Ebola virus and Kyasanur Forest disease.

Hence, recommendations $3 a, 3 b$, and $3 c$ are: 3a) Research be expanded on the co-evolution of ecosystems - including the microbial populations within them - over time. This will require the establishment of long-term sites in various parts of the world and incorporating various types of human activities. Such longterm sites have been set up for "pure" ecological studies; the bases for such teaching-learning sites have already been established in several on-going projects in various parts of the world. What is needed now is to rationalize these, give them some permanent long-term funding, and expand the range of researchers involved; 3b) That new health, economic, and environmental initiatives take into account possible long-term effects on the system dynamics; and 3c) That relatively uninhabited ecosystems be protected from further human invasions by economic and political policies until such a time as we have a fuller understanding of the nature of the infectious agents in the system as currently evolved.

\section{Achieving health for all: Beyond complexity, beyond 2000}

Because components of ecosystems interact in ways that undermine our ability to make predictions, in particular because of the kinds of phenomena associated with attractors and threshold changes, it is essential that anyone interested in sustainable health take a broad, ecosystemic approach. Furthermore, because of our limited ability to predict outcomes, it is important that we maintain our flexibility and our options.

In practical terms, this means that local bioand social diversity must be maintained as a way of maintaining some reserve to respond to the certain changes ahead. An ecosystem approach to emerging diseases, then, involves, on the one hand, monitoring changes in the structures of ecosystems which are leading to the creation of different and often larger niches for potential pathogens. On the other hand, it means working to stop the most dangerous of these changes - working to influence national and international economic and political policies which are creating the disease-promoting conditions. It means doing our research in such a way that the goals such as food security, health, and a convivial life can be achieved without threatening the ecosystems which provide the services that make human communities possible.

Because systemic descriptions and resolutions are context-specific, and because we are talking about bringing together multiple systems descriptions, some argue that the amount of time, energy, money, and work required to do this research is impossible in practice to achieve. This criticism is based on outmoded ideas of both research and development. Although the ecosystem approach to health requires a major commitment of people's activities, these activities are those which should already be going on in any society: planting crops, building bridges, educating children. Within an ecosystem approach, every policy decision is a hypothesis, and every management plan is a test of that hypothesis. Research becomes an integral part of the daily decision-making and evaluating activities of households, communities, regions, and global institutions. This is precisely what makes this an adaptive approach; it does not assume that Truth - relative to sustainability and health - can be established once-and-for-all with a few definitive experiments.

We define health at our boundaries - as individuals, communities, nations and global- 
ly - and we achieve health by communicating and negotiating across our boundaries. Think ecosystemically, act holarchically, should be the rallying cry of health workers around the world. There is good evidence that the ecosystem approach can help us achieve a global vision of health, but the uncertainty and contradictions which it is attempting to accommodate must ultimately be applied back to itself. If nothing else, the ecosystem approach brings home the deep understanding that we cannot

\section{Acknowledgments}

I would like to thank the International Development Research Centre (Montevideo) for their financial support. I would also like to thank James Kay, Tamsyn Murray, and other members of the Dirk Gently Group (Jerry Ravetz, Silvio Funtowicz, Mario Giampietro, Bruna de Marchi, Martin O'Connor, Gilberto Gallopin, Silvia Tognetti, Henry Regier, George Francis, NinaMarie Lister et al.) for keeping these debates alive.

\section{References}

ALLEN, T.; BANDURKSI, B. \& KING, A., 1991. The Ecosystem Approach: Theory and Ecosystem Integrity. Report to the Great Lakes Advisory Board, International Joint Commission, USA and Canada.

ALLEN, T. \& HOEKSTRA, T. W., 1992. Toward a Unified Ecology. New York: Columbia University Press.

BOCKING, S., 1994. Visions of nature and society: A history of the ecosystem concept. Alternatives, 20:12-18.

CAST, J. L., 1994. Complexification. New York: HarperCollins Publishers.

CHECKLAND, P. \& SCHOLES, P., 1990. Soft Systems Methodology in Action. John Chichester: Wiley \& Sons.

CONSTANZA, R.; NORTON, B. \& HASKELL, B., 1992. Ecosystem Health: New Goals for Environmental Management. Washington, D.C.: Island Press.

DUBOS, R., 1965. Man Adapting. New Haven: Yale University Press.

EVANS, R. G.; BARER, M. L. \& MARMOR, T. R., 1994. Why are Some People Healthy and Others Not? The Determinants of Health in Populations. New York: Aldine de Gruyter.

EWALD, P., 1994. Evolution of Infectious Disease. Oxford: Oxford University Press.

FARMER, P., 1996. Social inequalities and emerging infectious diseases. Emerging Infectious Diseases, 2:259-269. "manage" the planet for health, but we can look for opportunities to better adapt and feel at home - to be healthy - in an uncertain and contradictory world. Even if our hopes are misplaced, however, and the specific disease control and health outcomes we seek are not achieved, fundamental requirements of the ecosystem approach for open and democratic communication, tolerance, negotiation, and ecological awareness will surely have made the effort worthwhile.
FUNTOWICZ, S. \& RAVETZ, J., 1994. Emergent complex systems. Futures, 26:568-582.

GIAMPIETRO, M., 1994. Sustainability and technological development in agriculture: A critical appraisal of genetic engineering. Bioscience, 44:677689.

GITAU, T.; McDERMOTT, J. \& WALTNER-TOEWS, D., 1997. Design and implementation of a program to assess the health of an intensively farmed highlands agroecosystem in Kenya. Epidemiologie et Santé Animale, 31-32:2-7.

HOLLING, C. S., 1986. The resilience of terrestrial ecosystems: Local surprise and global change. In: Sustainable Development of the Biosphere (W. M. Clark \& R. E. Munn, eds.), pp. 292-320, Cambridge: Cambridge University Press.

KAY, J.; REGIER, H.; BOYLE, M. \& FRANCIS, G., 1999. An ecosystem approach for sustainability: Addressing the challenge of complexity. Futures, 31:721-742.

LAST, J. M., 1988. A Dictionary of Epidemiology. Oxford: Oxford University Press.

LEDERBERG, J.; SHOPE, R. \& OAKS, S., 1992. Emerging Infections: Microbial Threats to Health in the United States. Washington, D.C.: National Academy Press.

MARA, D. D. \& ALABASTER, G. P., 1995. An environmental classification of housing-related diseases 
in developing countries. Journal of Tropical Medicine and Hygiene, 98:41-51.

MAY, R., 1977. Thresholds and breakpoints in ecosystems with a multiplicity of stable states. Nature, 269:471-477.

MESLIN, F. X., 1997. Global aspects of emerging and potential zoonoses: A WHO perspective. Emerging Infectious Diseases, 3:223-228.

MINKIN, S. F.; RAHMAN, R. \& ISLAM, M. A., 1996. Flood control embankments and epidemic kalaazar in Bangladesh. Ecosystem Health, 2:215-226.

MURRAY, T.; KAY, J.; WALTNER-TOEWS, D. \& RAEZLUNA, E., 1999. Adaptive Methodology for Ecosystem Sustainability and Health (AMESH): An Introduction. Conference on Conservation Medicine, White Oak Conservation Center, Florida, April 29May 2.

PUCCIA, C. \& LEVINS, R., 1985. Qualitative Modeling of Complex Systems. Cambridge: Harvard University Press.

ROLING, N. G. \& WAGEMAKERS, M. A., 1998. Facilitating Sustainable Agriculture. Cambridge: Cambridge University Press.

SEVERINGHAUS, J. P. \& BROOK, E. J., 1999. Abrupt climate change at the end of the last glacial period inferred from trapped air in polar ice. Science, 286:930-933.

TAYLOR, K., 1999. Rapid climate change. American Scientist on the Web, 87 <http://www.amsci.org/ articles/99articles/taylor/html $>$.

UNDP (United Nations' Development Program), 1998. Overview of Human Development Report 1998. $<$ http://www.undp.org/wdro/e98over.htm>.
UNDP (United Nations' Development Program), 1999. Human Development Report. Oxford: Oxford University Press.

VanLEEUWEN, J.; NIELSEN, N. O. \& WALTNERTOEWS, D., 1998. Ecosystem health: An essential field for veterinary medicine. Journal of the American Veterinary Association, 212:53-57.

WALTNER-TOEWS, D., 1995. Changing patterns of communicable disease: Who is turning the kaleidoscope? Perspectives in Biology and Medicine, 39:43-55.

WALTNER-TOEWS, D., 1996. An agroecosystem perspective on foodborne illnesses. Ecosystem Health, 2:177-185.

WALTNER-TOEWS, D., 1999. Mad Cows and Bad Berries. Alternatives Journal: Environmental Thought, Policy and Action, 25:38-44.

WALTNER-TOEWS, D., 2000. The end of medicine: The beginning of health. Futures, 312:655-667.

WALTNER-TOEWS, D. \& WALL, E., 1997. Emergent perplexity: In search of post-normal questions for community and agroecosystem health. Social Science and Medicine, 45:1741-1749.

WELCH, R.; COMBS, G. \& DUXBURY, J., 1997. Toward a "greener" revolution. Issues in Science and Technology, Fall:50-58.

YASSI, A.; MAS, P.; BONET, M.; TATE, R.; FERNANDEZ, N.; SPEIGEL, J. \& PEREZ, M. L., 1999. Applying an ecosystem approach to determinants of health in Centro Habana. Ecosystem Health, 5:3-19. 


\section{Debate on the paper by David Waltner-Toews \\ Debate sobre o artigo de David Waltner-Toews}

\section{Luiz Jacintho da Silva}

Departamento of Medicina Faculdade de Ciências Médicas, Universidade Estadual de Campinas. Superintendência de Controle de Endemias, Secretaria Estadual da Saúde, São Paulo. ljsilva@sucen.sp.gov.br
Pavlovsky revisited. New clothes for ecology in epidemiology. A commentary on An Ecosystem Approach to Health and its Applications to Tropical and Emerging Diseases, by David Waltner-Toews.

The ecological approach to understanding disease dynamics in populations is at least as old as Hippocrates (Hippocrates, s.d.). From Hippocrates until the dawn of the bacteriological era, disease theory was mostly ecological in nature (Galen, s.d.). In fact, not truly ecological according to the current scientific definition, but ecological in nature. According to the Hippocratic definition, an endemic was a disease determined by the nature of a certain place. Demos had a broad meaning, and could be understood as people or population, but also as place, home. Under this definition, climatic, hydrological, and behavioral determinants were seen as the main forces. This view of disease occurrence and distribution persisted for centuries. Hippocrates' writings were recycled by Galen (Galen, s.d.) in the early Christian era and resisted even the Galilean modernization of science during the Renaissance, surviving as the mainstay of medical and public health science until the late 18th century. Hippocrates and Galen are not the main subject of discussion here, but it must be noted that their concept of disease was ecological. Disease was a consequence of local conditions, which had to be favorable for a particular disease to occur. Diseases were named after the respective scenarios in which they occurred, such that different scenarios gave rise to different diseases.

Pavlovsky (Pavlovsky, s.d.), a little-known parasitologist from what was then the Soviet Union, can be considered one of the first to propose a reasonably well-structured theory of infectious disease ecology. Unfortunately, in the late 1930s Soviet epidemiology (and indeed Soviet science as a whole) were not very well known in the West, and Pavlovsky's theory of the natural nidality of transmissible diseases had a very restricted circulation (Audy, 1958; Marr, 1995). Nonetheless, Pavlovsky succeeded in furthering the understanding of disease occurrence and the consequences of ecosystem modification. Unfortunately Pavlovsky did venture too far forward, since he appeared to be satisfied with understanding leishmaniasis and the then-emerging tick-borne encephalitis.

We can, with reasonable confidence, accept that the ecosystem approach to infectious diseases began with Pavlovsky. Waltner-Toews' article presents ecosystem analysis as a recent invention, which it is not. A large number of researchers have employed one or another method of ecosystem analysis for understanding and controlling infectious diseases (Audy, 1958; May, 1958; Burnet et al., 1972; Croll et al., 1983; Blower et al., 1991). In fact, the extensive use of the term "tropical" to define a broad array of diseases is inappropriate. Globalization has erased boundaries between endemic and disease-free areas; these diseases are not a prerogative of tropical ecosystems, albeit the latter are doubtless extremely favorable to their occurrence.

What distinguishes contemporary ecosystem analysis of diseases is the ecological paradigm adopted (Science et Vie, 1996; Earn et al., 1998). Virchow, cited by Waltner-Toews, concluded the obvious. Appalling living conditions in mid-19th century Silesia made the association obvious; it was not the result of scientific reasoning, but only of sound common sense. The failure of post-War economic development projects in the Third World and of large disease-control programs preceded the late 1970s debt crisis. The Marshall Plan had been a success in Europe; malaria eradication was also a success in Southern Europe and the Southeastern United States, but fell short of its objectives in the Third World. Worse yet, many development projects, like irrigation schemes and hydroelectric dams, caused diseases to spread (Hughes et al., 1970; Gordon-Smith, 1975). Cultural traits of target groups conflicted with behavioral changes needed for disease control. It gradually became obvious that infectious disease control programs demanded a more comprehensive approach than the prevailing linear reasoning.

The ecosystem approach proposed by Waltner-Toews is no doubt interesting, but the theoretical basis is not clearly presented. Modern ecological theory differs from Pavlovsky's. Modern science has abandoned the passion for precision to embrace a love of the imprecise, the uncertain. Chaos theory is finding its place in virtually all scientific disciplines (Hénon, 1989; Casti, 1995; Science Illustrée, 1996; Earn et al., 1998). Waltner-Toews commits a Freudian slip when he discusses attractors and catastrophic changes, which are an integral part of 
chaos theory. Waltner-Toews' ecosystem approach is more than a cookbook recipe for understanding and controlling infectious diseases, but this is not made clear as he expounds on its theoretical base. Public health needs a sounder theoretical base, and ecosystem analysis is a major step towards raising epidemiology to the same level of philosophical soundness as physics. Public health must be wary of "new" approaches. Infectious disease control has advanced enormously in its technical aspects, but the latter have still proven to be insufficient. A more appropriate understanding of disease is needed, and Waltner-Toews comes close. However, he appears to be distracted by the siren's song of the biased world view still prevailing in many scientific circles in industrialized countries. Infectious diseases must be seen as a whole, not divided into tropical and non-tropical, meaning in fact underdeveloped and developed. Waltner-Toews proposes a distinction between tropical and non-tropical diseases, according to which the former frequently " $o c$ cur in settings where the links between local ecosystems and local communities are intense and obvious." [quoted from a preliminary version of the article]. Links between ecosystems and communities are hard to understand, as communities are integral parts of ecosystems. Here lies another Freudian slip, since ecosystem is seen as merely the natural ecosystem, detached from human presence.

The ecosystem approach presented by Waltner-Toews is appealing, but unfortunately infected by a biased view of the developing world.

AUDY, J. R., 1958. The localisation of disease with special reference to the zoonoses. Transactions of the Royal Society of Tropical Medicine and Hygiene, 52:308-328.

BLOWER, S. M. \& McLEAN, A. R., 1991. Mixing ecology and epidemiology. Proceedings of the Royal Society of London B Biological Sciences, 245:187-192.

BURNET, M. \& WHITE, D. O., 1972. The ecological point of view. In: Natural History of Infectious Disease (M. Burnet \& D. O. White, eds.), pp. 1-21, 4th Ed., Cambridge: Cambridge University Press.

CASTI, J. L., 1995. Complexification. Explaining a Paradoxical World Through the Science of Surprise. New York: Harper Perennial.

CROLL, N. A. \& CROSS, J. H., 1983. Human Ecology and Infectious Diseases. New York: Academic Press.

EARN, D. J.; ROHANI, P. \& GRENFELL, B. T., 1998. Persistence, chaos and synchrony in ecology and epidemiology. Proceedings of the Royal Society of London B Biological Sciences, 265:7-10.

GALEN, s.d. On the Natural Faculties. < http://classics. mit.edu/galen/natfac.html>.

GORDON-SMITH, C. E., 1975. Changing patterns of disease in the tropics. In: Man - Made Lakes and Human Health (N. F. Stanley \& M. P. Alpers, eds.),

pp. 345-362, London: Academic Press.

HÉNON, M., 1989. La diffusion chaotique. La Récherche, 20:490-498.

HIPPOCRATES, s.d. On Airs, Waters, and Places. <http: //www.classics.mit.edu/Hippocrates/airwatpl. html>.

HUGHES, C. C. \& HUNTER, J. M., 1970. Disease and "development" in Africa. Social Science and Medicine, 3:443-493.

MARR, J., 1995. The natural nidality of transmissible diseases: Searching for the "MacGuffin". <http:// www.medscape.com/medscape/f...es/1997/ms0 01.marr/ms001.marr.html>.

MAY, J. M., 1958. The Ecology of Human Disease. New York: M. D. Publications.

PAVLOVSKY, E. N., s.d. Natural Nidality of Transmissible Diseases. Moscow: Peace Publishers.

SCIENCE ET VIE, 1996. L'écologie. Cent ans d'adolescence. Science et Vie, 949 (octobre):84-87.

SCIENCE ILLUSTRÉE, 1996. Nous vivons au bord du chaos. Science Illustrée, 12 (décembre):50-55.

Maj-Lis Follér

Ibero-American Institute, Göteborg University. majlis.foller@ibero.gu.se
David Waltner-Toews (W-T) has chosen to discuss an issue of fundamental importance, the role of environmental change and how it relates to human health, i. e., how to combine the socioeconomic and biophysical dimensions of human health. It is a complex challenge to grasp how relations between ecosystems are connected and influence the everyday life, health, and welfare of human beings. W-T applies an ecosystem approach to this task in his article.

In the introduction he asks, "What is health"? He mentions the World Health Organization's definition “...as a state of complete physical, mental, and social well-being, and not merely the absence of disease". W-T is critical of this definition. What he suggests is a redefinition of health as "absence from disease and pathology". I find this confusing in relation to the holistic ecosystem approach presented later in the article. For me, the above statement is a perception of health as a static and biomedical condition. I would have preferred another introduction, since this definition certainly stands apart from the rest of the article, and he never really returns to the meaning behind this redefinition.

If $\mathrm{W}$ - $\mathrm{T}$ intends to discuss the WHO policy starting with the 1948 founding document, such a discussion must be placed in some form of historical context, since the document is clearly biomedical and born within Western 
tradition. For W-T's overall global and ecosystem approach to health, I find more relevant a continuation of the Alma-Ata Declaration, which is now more than 20 years old, but which certainly focuses more on the importance of community involvement for improving health conditions. In a world of limited resources, mass unemployment, and health standards that are socially and economically far removed from such aims for the majority of the world population, neither the idealistic WHO definition nor that proposed by $\mathrm{W}-\mathrm{T}$ provides a realistic starting point. Such ideal statements sound strange and dangerous in relation to my way of dealing with today's reality. They have the potential of creating new problems in establishing for whom and on what level in society the absence of disease or pathology can be defined. The WHO definition of health is part of the Western tradition and implies the notion of perfectibility. I would suggest a more processual view of the continuum between health and disease in the introduction, since this is what the author emphasizes later on in the article. We are all born, live, and die, and during this process we must deal with physical, emotional, and psychological strain. This is part of life, and only on an individual level can one decide whether to define one's situation as illness. This is valid for people with disabilities, those defined by society as mentally ill or abnormal, and persons with stress-related disease.

At any rate, $\mathrm{W}$-T applies an ecosystem approach to health in the rest of the article. He defines a system as a set of elements which interact with each other within certain boundaries. He elaborates on the concepts of holarchy, attractor, and complex feedback loops, all central to understanding an ecosystem approach. Systems that are hierarchically nested within each other are called holarchical. As I understand the ecosystem approach, the point with concepts such as holarchies is to show that there is always interdependence between subsystems and supersystems. Central to this approach is that there is a systematic function; the supersystem is dependent on continuous cooperation with the subsystem. This is translated into another terminology by which everything is related to everything else, and the focus of this article is the relationship between global and local concerns in today's world. W-T makes these relations more transparent by giving examples of the importance of local activities and how they interfere with and influence global activities. That is to say, there is an interconnectedness between the holarchy of the ecosphere, ecosystems, and human systems, hence the connections between human health and ecosystem health.

I agree that we need some form of holistic approach for the integration of social, economic, and environmental interests in relation to human health in a systematic way. But even with this very broad approach to connect ecosystem health and human health, W-T does not talk about interdisciplinarity or how to establish cooperation between scientists. W-T writes, "Both scientific studies and participatory action research (PAR) are necessary ingredients of an ecosystem approach, and both must be reoriented to a systems understanding of reality." This is a huge task, but I agree that we have to begin the dialogue. The question is how to elaborate communications between people living in rural communities around the globe and researchers in a two-tier way. On the one hand, taking local knowledge seriously, and on the other, translating and making scientific knowledge understandable to people in rural areas of the world. W-T also writes, "How can we do scientific research and science-based development in support of health?" $\mathrm{W}$-T gives examples to show that medical sciences both solve and create problems, displaying a certain humbleness of mind, which I like.

I believe that we need broad scientific cooperation among scientists from ecology, medicine, and social and cultural disciplines to solve many of today's health problems. But local participation and elaboration of dialogue with people in the communities are just as important. They often have concepts of health that go beyond merely the physical functioning of individuals. As I interpret it, this is also the intention behind W-T's approach, but he misses some of the "soft" aspects, such as the behavioral and cultural dimensions of people living in the communities. They are the ones affected by tropical, emerging, and other diseases.

Still, the author has taken an important step in this article in attempting to connect an ecosystem approach to different aspects of health-related issues, even though he deals largely with patterns of infectious and emerging diseases. $\mathrm{W}$-T attempts to cross borders between ecological, sociological, and medical sciences and participatory action research. We know that there are linkages between human activities and alterations in ecosystem functions and services with direct consequences for disease transmission and some more indirect effects, and $\mathrm{W}$ - $\mathrm{T}$ highlights some of these connections.

We are now more than 6 billion people living on the planet Earth. If we want a sustain- 
able future, different strata in society must work together. As scientists, we have to cross disciplinary borders to find new connections and black holes in our knowledge and understanding of the relationship between global processes, local impact, and individual behavior. W-T has taken one step in this direction, and more discussion is needed. The debate that took place in Rio de Janeiro during the IDRC meeting in November 1999 between ecologists, human ecologists, social scientists, medical scientists, development organizations, and PAHO representatives was a good initiative. It is through the creation of interdisciplinary forums and an open dialogue that we will realize that no one has a single all-encompassing competence for a sustainable future. We have to learn from each other and hopefully be part of a process which moves the contemporary and future ecosystem and human health situation in a positive direction.
Emilio F. Moran

Indiana University Blomington, Indiana, United States of America.
The discussion by David Waltner-Toews covers considerable ground and is stimulating as a whole. It correctly diagnoses our contemporary problems as stemming from sectoral and disciplinary thinking, with all the inevitable blinders. Indeed, he reviews the frequent failures that result when we mean to do good but fail to foresee the consequences of our interventions at higher or lower levels in complex system hierarchies.

I was particularly taken by his Table 4 of recommendations, which seem to be sensible and appropriate as first steps to health in the new millennium. There can be little quarrel with the author that we need more complex systems thinking or that this approach (together with participation by the populations affected in the process) is likely to lead to better health outcomes. My main critique of the author is that he fails to provide either details on how his Great Lakes Basin program or the Dirk Gently Group are attempting to implement this approach or evidence for improved outcomes from such efforts.

Without evidence for how a SOHO approach leads to improved health and well-being, it is unlikely that its adoption will follow. There are many inherent difficulties in the approach that must be dealt with (and the author only rarely alludes to them): divergent and/or competing interests among sectors of the human community; the free-rider problem; the challenge of building robust institutions based on trust and reciprocity (in a world where these are increasingly scarce); mechanisms for allocating costs in multi-tier systems, etc.

In other words, the sectoral model has prevailed because it makes it easier to manage simple, single-tier systems created to facilitate operations, allocate charges, and produce reasonable results (while ignoring upstream and downstream consequences). The proposed SOHO approach is conceptually more attractive but riddled with all kinds of new challenges for its "managers" or modelers. Particularly if such systems are non-linear and chaotic (as they must be), the uncertainty of outcome in itself is a political challenge for those who wish to implement it. Most human communities are not likely to be receptive to outcomes characterized by uncertainty. The author and his colleagues need to move from the appealing conceptual and diagnostic stage to an operational model if we are to hope for implementation of this idealistic goal in the 21 st century. We certainly need alternatives to health and business as usual. 


\section{Cristina de Albuquerque Possas}

Escola Nacional de Saúde Pública, Fundação Oswaldo Cruz.
In this interesting article Waltner-Toews discusses the notion of ecosystem health and the insights it can provide for confronting the emergence and complexity of infectious diseases. According to him, those who possess the skills required to prevent and treat disease are ill-equipped to promote health. As some authors have pointed out before (Levins et al., 1994) he notes that disease prevention and control programs tend to ignore complexity and may, in fact, create ill-health. In his view, these failures result from our limited ability to predict outcomes and from our incapacity to account for holarchy and to understand non-linear interactions, chaotic attractors, and catastrophic thresholds in complex ecosystems.

Background information is necessary to understand the contributions and possible limitations of the ecosystem health approach proposed in this article. The notion of ecosystem health was first introduced by Rapport (1989) in an international meeting of the Association for Great Lakes Research and was developed later in other publications. In 1994, an international workshop on Agrosystem Health was organized by the University of Guelph with the support of IDRC. The discussions focused then on the contributions of the health paradigms to understand agroecosystems: vigor, resilience, and system organization, as suggested by Constanza (1994), and on the comparative advantages of the ecosystem. health concept over sustainability.

According to some authors (Smit \& Smithers, 1994), for practical purposes the concepts were essentially the same, while other authors (Waltner-Toews, 1994) suggested that the health paradigm could provide a more appropriate basis for thought and action in agroecosystems. In this workshop, it was noted that sustainability and ecosystem health are tightly connected but are distinct concepts and that their more exact relationship remained to be determined.

Simultaneously, in the health field, some research groups developed ecosystem approaches to emergence and resurgence of infectious diseases worldwide. In 1991, in the United States, the Harvard New Diseases Group started a transdisciplinary research agenda in this area. Contributions were published later in the Annals of the New York Academy of Sciences (Wilson et al., 1994) and in other publications.

The issues discussed in Waltner-Toews' article can therefore be explored from two distinct epistemological perspectives: the ecologist's viewpoint, the contribution and usefulness of the health paradigm to understand and intervene on complex ecosystems; the public health perspective, the contribution of the ecosystem health notion (or metaphor, as suggested by Gallopín, 1994), to understanding and confronting the complexity of epidemiological profiles and the emergence of diseases.

First, some ecologists view the incorporation of the health paradigm for ecosystem research and monitoring change to maximize ecosystem health as problematic (Gallopín, 1994). The definition of health is crucial here. If health is defined as something that might be kept constant ("people die and ecosystems evolve"), then the notion of ecosystem health would not be appropriate to deal with sustainability in a dynamic and changing world. In contrast, other arguments, as proposed by Waltner-Toews in this article, provide a definition of health that can be broader, incorporating into this approach the notions of balance and harmony on the one hand and capacity to respond to changing environments on the other. From this perspective, the notion of ecosystem health can provide interesting insights.

Second, from the public health perspective the issues concerning the contributions of ecosystem health are even more complex. On the one hand, the ecosystem health notion can provide a crucial and missing ecosystem approach to understand the complexity of epidemiological profiles and the emergence of diseases. On the other, in a world where the economy and societies are being transformed by accelerating globalization and local policy communities are gaining political and economic power, it is important to stress that the conceptual force of the ecosystem health approach will certainly depend on our capacity to incorporate these social and political dimensions into a new theoretical framework.

Ecosystems have become complex social ecosystems (agro-industrial ecosystems and urban ecosystems) increasingly transformed by human activities, interacting and expanding in ways never before imagined. Globalization is increasing local demands for political power and participation, stimulating pressures for social inclusion in sustainable development, particularly in developing countries where social exclusion and poverty are dramatic. Therefore, monitoring change in the structures of ecosystems leading to niches for potential pathogens to emerging diseases, as proposed by WaltnerToews, requires a new approach. On the one hand, ecological frameworks consider the variability of the physical and biotic environment but tend to homogenize people without taking into account different social systems, classes, 
or even the commodity as a physically powerful social construct, tending to omit social aspects of survival. On the other, the social sciences correspondingly make use of social differentiation without linking it to patterns of exposure and vulnerability to the biological and physical environment.

Contributions by the social and political sciences to understanding and dealing with the macro-processes permeating ecosystems and health reform strategies should be integrated into a new "social ecosystem health" paradigm (Levins et al., 1994; Possas \& Marques, 1994; Levins \& Lopez, 1999). Bringing together the socioeconomic and biophysical dimensions of health and trying to understand how social and ecological variables appear to behave in complex systems, as Waltner-Toews has suggested, require more than incorporating these new elements into theory. It is necessary to bridge in a new theoretical framework the conceptual and methodological gaps between paradigms from social sciences and ecology, which have historically been kept apart.

CONSTANZA, R., 1994. Supplementary comments on the concept of ecosystem health. In: Agroecosystem Health: Proceedings of an International Workshop (N. O. Nielsen, ed.), pp. 29-30, Ottawa: University of Guelph/IDRC/CGIAR.

GALOPIN, G. C., 1994 Agrosystem health: A guiding concept for agricultural research?. In: Agroecosystem Health: Proceedings of an International Workshop (N. O. Nielsen, ed.), pp. 51-65, Ottawa: University of Guelph/IDRC/CGIAR.

LEVINS, R.; AWERBUCH, T.; BRINKMAN, U.; ECKARDT, I.; EPSTEIN, P.; MAKHOUL, N.; POSSAS, C. A.; PUCCIA, C.; SPIELMAN, A. \& WILSON, M. E., 1994. The emergence of new diseases. American Scientist, 52:60.

LEVINS, R. \& LOPEZ, C., 1999. Toward an ecosocial view of health. International Journal of Health Services, 29:261-293.

POSSAS, C. A. \& MARQUES, M. B., 1994. Health transitions and complex systems: A challenge to prediction? Annals of the New York Academy of Sciences, 740:285-296.

RAPPORT, D. J., 1989. What constitutes ecosystem health? Perspectives in Biology and Medicine, 33: 120-132.

SMIT, B. \& SMITHERS, J., 1994. Sustainable Agriculture and Agroecosystem Health. In: Agroecosystem Health: Proceedings of an International Workshop (N. O. Nielsen, ed.), pp. 31-38, Ottawa: University of Guelph/IDRC/CGIAR.

WALTNER-TOEWS, D., 1994. Ecosystem health: A framework for implementing sustainability in agriculture. In: Agroecosystem Health: Proceedings of an International Workshop (N. O. Nielsen, ed.), pp. 820, Ottawa: University of Guelph/IDRC/CGIAR.

WILSON, M.; LEVINS, R. \& SPIELMAN, A., 1994. Disease in Evolution. Annals of the New York Academy of Sciences, 740 .
José Maria G. de Almeida Jr.

Universidade de Brasília.
There are three main types of world views: holistic, fragmentary, and fractal (Almeida Jr., 1994; Almeida Jr., in press). The ecosystem approach is by definition holistic, because it takes abiotic, biotic, and cultural factors into account, along with a flow of matter and energy across space and time. Accordingly, the concept of holistic health (or, for that matter, ecosystem health) involves all the patient's mental and family circumstances (social, economic, etc.) rather than just the physical and biological aspects of disease.

There is no doubt that Waltner-Toews' ecosystem approach to health deals with the subject as a whole rather than merely examining it in a fragmentary way. But what about mind in his model? The lack of this dimension is, in my opinion, the central weakness of his otherwise intelligent, instructive, and useful paper.

It seems to me that the author fails to take the reality of mind into account (at least in an explicit way) in keeping with the scientific tradition of not dealing with elusive categories. This is a regrettable mistake. For example, what can be said of hard epidemiological data on high blood pressure caused by hidden emotions (Mann, 1999)? Or eye movement desensitization and reprocessing (EMDR) as a powerful psychological procedure, developed mainly by Shapiro (1995) as a therapy for overcoming anxiety, stress, and trauma?.

The fact is that the role of mind-body interaction in health and disease is so well recognized today (Benson \& Marg, 1996) that it must be incorporated into any health-disease model, especially a holistic one.

In addition to the above general remark, I wish to propose some questions to the author:

1) How does the ecosystem approach to health relate to (1) gene therapy, (2) transgenics, and (3) cloning?.

2) "Many tropical diseases are thus not only diseases related to climate and environment, but are diseases of poverty." In making this conflictive affirmation, it seems that Waltner-Toews does not really believe in tropical diseases as diseases of poverty.

3) How does the author fully explain Dubos' formidable "mirage of health" concept (Dubos, 1959) in light of the proposed ecosystem approach to health, particularly with respect to emerging diseases?

4) Waltner-Toews' ecosystem model of health is part of an overall view of sustainable development. It would be interesting to know the 
author's opinion of an international effort towards that end.

ALMEIDA Jr., J. M. G., 1994. Desenvolvimento ecologicamente auto-sustentável: Conceitos, princípios e implicações. Humanidades, 38:284-299.

ALMEIDA Jr., J. M. G. Holística: Por Uma Visão Estratégica de Desenvolvimento Ecologicamente AutoSustentável. (in press)

BENSON, H. \& STARK, M., 1996. Timeless Healing. New York: Scribner.

DUBOS, R., 1959. Mirage of Health. New York: Harper.

MANN, S. J., 1999. The Hidden Cause of High Blood Pressure - Changing the Myths. London: Thorsons.

SHAPIRO, F., 1995. Eye Movement Desensitization and Reprocessing - Basic Principles, Protocols, and Procedures. New York: Guilford.
Anthony J. McMichael

London School of Hygiene and Tropical Medicine.
This paper addresses a complex topic: the "ecosystem approach to health". We health scientists can readily lose our way among some of the concepts in this unfamiliar domain. We are, frankly, not used to thinking of health and disease within an ecosystem-based framework; we prefer to attribute disease causation to events or processes that arise and act at the level of the individual. This, for half a century, has been the dominant expectation of epidemiologists, and their methods are well-honed to this expectation.

Scientists in the Western world are the intellectual heirs to three centuries of a very different conceptual framework, that is, Newtonian science that views the world as a mechanical system amenable to reductive analysis. This has been the science of disaggregation, quantification, and assumed orderliness; the science that assumes a gradualist relationship, wherein a small change in the initial conditions of some process will cause a small effect, while larger changes will induce larger effects. This is the scientific tradition within which doctors "have sought to localize disease within the body, to identify specific pathological lesions, first in organs, then in tissues, then cells and now molecules... A germ, toxin, or gene can be held to account for most ailments, and the importance of predisposition, constitution, and social or environmental circumstances has diminished" (Anderson, 1999:49).

This conventional biomedical view is not wrong. But it is only part of the story - and per- haps not even the most important part. A larger question for epidemiologists is to understand why disease rates rise and fall over time, why some populations have different rates from others. Such questions are best answered when there is recognition that the health of a population is an ecological index - that is, it tells us about the balance between that population's biological needs and the capacity of the environment to meet those needs. In the longer term the level of a population's health reflects the adequacy of the carrying capacity of the environment. If we are slow to appreciate this, it is largely because humankind's cultural devices, especially technological adaptations and the buffering effects of imports, modulate the environmental carrying capacity; for humans (in contrast to other wild species) the carrying capacity is not externally fixed.

This paper alludes to the ecological dimension of human health. It describes, for example, how environmental interventions by human societies alter the risks of transmission of various infectious diseases. The theoretical base for "ecosystem health" is presented in terms of nested relationships - holarchies - and the interdependencies between levels and components. Nevertheless, the paper fails to make quite clear just what is the "ecosystem approach". Is this because that approach cannot be defined so much as intuited from a generic understanding of how ecological systems and processes work? Is this a phenomenon that is subject to multiple interpretations, one that takes us into the uncertain and chameleon-like realm of non-normal science (Funtowicz \& Ravetz, 1994)?

Elsewhere, Waltner-Toews and colleagues have surveyed the historical progression of attempts to model influences on human states of health (VanLeeuwen et al., 1999). The earliest model, from the 1930s, was the classical triangular host-agent-environment model which elaborated the specific, one-agent-one-disease Germ Theory. In the 1950s, the British epidemiologist Jerry Morris propounded a social-ecological model in which the host was differentiated into genetic and experiential components, the environment was differentiated into physical and social, and the "agent" became behaviors of the person. Here was a pioneering integrative view of how diseases such as heart disease arose within modern urban society - this was social realism, but with no explicit recognition of the role of the natural environment and its life-support systems. In the 1970s and 1980s various attempts were made to extend these models, within a social-environmental 
context. These mandala-like models recognized nested layers of influence, interactive processes between those layered factors, and the several dimensions of "health" - physical, mental, and spiritual. In the 1990s a more elastic, permissive, "butterfly" model of biophysical and social-psychological influences on physical, mental, and spiritual health has been propounded (Bormann, 1996).

And so we enter the 21 st century, having progressed from simplicity, linearity, and boxes-and-arrows to complexity, multidirectionality, and porous, interacting spheres of influence. This leads us to talk more comfortably of "life course epidemiology" and to seek an "ecosystem approach" to health. The Newtonian mold has been broken, though not discarded. This is what Wulff (1999:50) has referred to as the impending return of biomedicine towards the Aristotelian world view, "the theories about open self-organizing systems, chaos, fractals and non-linear dynamics [that] have already provided new and important insight into the mechanisms of nature".

We get further clues later in this paper. Waltner-Toews says we must use both current description and an evolutionary understanding. Positivism is inappropriate. We must have a "feel" for why the system is like it is, and a feel for what "health" (as an index of biological functioning within the system context) signifies. The issue is clarified as he explores the meaning of "ecosystem health" for infectious disease: "What distinguishes many so-called tropical diseases is that they occur in settings where the links between local ecosystems and local communities are intense and obvious." [quoted from a preliminary version of the article].We can, he says, replace Linnaean branching classification with generic groupings based on common ecological origins, e.g., housing-related infectious diseases in developing countries. We can see more clearly the interplay between local and global needs. We see the environment as an interactive medium; like Heraclitus' river, it is never the same twice. We also begin to see that disease and death are part of a larger, healthy, ongoing ecological narrative, with the succession of generations.

Finally we see more explicitly the political dimension to all of this, the dimension that goes beyond phenomenological description. This may shock the purist ecologist. But, then, we are talking about the human animal, the species that supplements "nature" (genes) with "nurture" (cumulative culture). Waltner-Toews says that: "The ecosystem approach is a way to bring together the socioeconomic and biophysi-

cal dimensions of health. Nevertheless, what it brings to our understanding of emerging diseases is not so much a way of identifying new variables - though it certainly forces us to cast our net much broader than in conventional research - but a new way of organizing how we think about them and respond to them."

We are not yet very good at thinking in terms of complex systems dynamics, in terms of holarchical relationships, nor within a longterm time frame. Striving for an ecosystem view of human health and disease requires us to understand these concepts. Faced by the challenge of finding ecologically sustainable ways of living for over six billion people, this understanding of human population health is essential. This paper helps us along that path - a path that requires some large-frame humility, not small-frame biomedical hubris. In WaltnerToews' words: “Within an ecosystem approach, every policy decision is a hypothesis and every management plan is a test of that hypothesis."

ANDERSON, W. H., 1999. Perception of disease and its meanings. Lancet, 354(Sup.4):49.

BORMANN, F. H., 1996. Ecology: A personal history. Annual Review of Energetics and Environment, 21:1-29.

FUNTOWICZ, S. \& RAVETZ, J. R., 1994. Emergent complex systems. Futures, 26:568-582.

VAN LEEUWEN, J. A.; WALTNER-TOEWS, D.; ABERNATHY, T. \& SMIT, B., 1999. Evolving models of human health towards an ecosystem context. Ecosystem Health, 3:204-219.

WULFF, H. R., 1999. The concept of disease: From Newton back to Aristotle. Lancet, 354:SIV49.

William E. Rees

School of Community and Regional Planning, University of British Columbia.

\section{Commentary: an ecosystem approach to survival}

“...human civilization - primarily Western technoindustrial urban society - will self-destruct, producing massive ecological damage, social chaos, and megadeath." (Smith \& Sauer-Thompson, 1998).

David Waltner-Toews presents a strong case for ecosystemic thinking - indeed socio-ecosystemic thinking - in the future control of tropical and emerging diseases. Several key points stand out, particularly the association of many diseases with poverty (exposure to vectors under crowded, unsanitary conditions); the multiple disease-favoring effects of the ecosystem 
disruption accompanying the expansion of human activities, and the growing recognition that "normal" predictive (Newtonian) science is an inadequate foundation for either population heath or ecosystem management. Indeed, the behavior of complex dynamic systems demands humble recognition that the best strategies for maintaining population health are likely to be those that enable society to adapt with minimal damage to unanticipated systems change.

If the paper has a major substantive flaw it lies in its paradoxically near-static approach to the dynamic systems it is analyzing. There is little reference to the rate or nature of global change. Certainly the ecosystemic approach would be a powerful tool if the world were in ecological steady-state, but Waltner-Toews' arguments are all the more compelling in the real world of dynamic change.

And this is definitely a world of dynamic change - the past two centuries have seen the massive expansion of the human enterprise on the one hand, accompanied by the precipitous erosion of ecosystems and the life-support services they provide, on the other. Most critically from the perspective of socio-ecological disease control, this anthropogenic explosion/ implosion continues unabated. Much of the contemporary world is currently 'enjoying' an unprecedented stretch of continuous material growth. Indeed, the global economy has tripled in size and the human population has ballooned by $30 \%$ to six billion since 1980 . Meanwhile in the course of industrialization, half the world's forests have been logged or converted (rate:130,000 $\mathrm{km}^{2} \mathrm{yr}^{-1}$ ); half the land on earth has been modified for human use; half the world's wetlands have been lost; $70 \%$ of its major fish-stocks have been placed in jeopardy; atmospheric carbon dioxide has risen $30 \%$ and climate change is upon us; and biodiversity loss is accelerating (extinction is now at least 1000 times the "background" rate).

Mindful of the emerging possibility of catastrophic systems "flips", Waltner-Toews recommends research that will identify and protect "holarchic boundaries" to avoid critical systems being drawn into "new attractors", and policies that will protect relatively pristine ecosystems from "human invasion". He also recognizes that we must address the chronic poverty that exposes ever greater absolute numbers of people to new and emerging diseases. However, he provides no indication of how these policies might be implemented or whether they can succeed on a finite planet dedicated to material growth.
These are not trivial questions. Should prevailing growth rates continue, we can expect an additional five-fold expansion of economic output and up to four billion more members of the human family by 2050 . Given the prevailing values of consumer society, the massive expansion of the human enterprise necessarily means the continuing dismantling and contraction of nature (Rees, in press). Feeding the expanding population requires the invasion and destruction of pristine ecosystems; globalization commoditizes nature while marginalizing the nonmarket - but vital - life-support functions it provides; liberalized global trade and exportled 'development' create economic incentives to over-exploit resource systems; production agriculture and forestry homogenize natural ecosystems and impose unstable monocultures that can be maintained only at great economic and material cost. Meanwhile, despite the unprecedented expansion of the economy, a quarter of humanity still lives in abject poverty and is increasingly at risk from environmental collapse and accompanying disease. (The widening income gap poses an unprecedented moral challenge to the world. In 1960, the richest fifth of humanity earned 'only' thirty times as much as the poorest fifth; by 1990 the ratio was about 60:1 (UNDP, 1994) and is on its way to $90: 1$ today.) In short, all the factors WaltnerToews identifies as favoring ecosystems collapse and new diseases, are running amok across the planet.

The destabilizing effect on the ecosphere is beginning to show. According to the International Red Cross's 1999 World Disasters Report, singular events such as Hurricane Mitch and the El Niño weather phenomenon, plus declining soil fertility and deforestation, drove a record 25 million people from the countryside into crowded, under-serviced, disease-ridden shantytowns around the developing world's rapidly growing cities. This is $58 \%$ of the world's total refugees. The Report predicts that developing countries in particular will continue to be hit by super-disasters driven by human-induced atmospheric and climatic change, ecological degradation, and rising population pressures. This is a recipe for a global population health calamity. As Waltner-Toews writes, "the ecosystem approach brings home the deep understanding that we cannot "'manage' the planet for health..." (my emphasis). Let us hope it also brings home the understanding that humanity's best chance for survival with dignity rests with our learning better to manage ourselves. 
REES, W. E. Patch disturbance, eco-footprints, and biological integrity: Revisiting the limits to growth. In: Ecological Integrity: Integrating Environment, Conservation and Health (D. Pimentel \& R. Noss eds.). Washington, D.C.: Island Press. (in press)

SMITH, J. W. \& SAUER-THOMPSON, G., 1998. Civilization's wake: Ecology, economics and the roots of environmental destruction and neglect. Population and Environment, 19:541-575.

\section{Maurício L. Barreto}

Instituto de Saúde Coletiva, Universidade Federal da Bahia.

\section{Interventions in the environment and society in the quest for health: how scientific can we be?}

There is no doubt that one of the current characteristics of many scientific fields is to seek all-encompassing models capable of providing more convincing and useful explanations for the phenomena under study. No matter how much I reflect on the notion that science can develop itself on its own strengths, I take a firm stand with those who view science as fundamentally tied to the search for solutions to concrete problems, even though this may require investigative projects in the short, medium, long, and very long terms. Such effort can be understood as one of the most useful exercises in strategic planning, and as such the undertaking entails risks, since of course part of the effort fails to materialize in the form of actual products. At any rate, we may always ask: a solution to what? a solution for whom? The article under debate aims a cutting but fair critique at the biomedical models flourishing around disease. In such models the idea of health, no matter how embellished it may be, is never understood beyond the notion of cure (or prevention of disease at most). Such models are hardly useful whenever one thinks of health as something positive (and here it is unnecessary to repeat the well-known WHO definition) rather than as the mere absence of disease. If we do think along these lines, we can only ask what should be done by all those who criticize, find fault, or even abhor such models? Of course this question is asked frequently, but the answer is not at all easy (Barreto, 1998). For example, in a recent review of the child health issue, Ehiri \& Prowse (1999) discuss the extent to which preventive and promotional programs reflect the Western medical care model, with little emphasis on child health's environ- mental and social dimensions, even though it is the object of extensive discussion and apparent consensus.

The biomedical model is reaffirmed daily by immense research and intervention structures, based on an enormous and lucrative industrial and services framework, worshipped by many, but considered scarcely useful and even iatrogenic by (a few) others. Considering the scientific research component alone in the United States, the National Institute of Health alone invests 14 billion dollars a year. But we do not have to look that far for examples, since in Brazil the scarce resources for health allocated through the Ministry of Health and its affiliated institutions basically serve to reaffirm this same Western biomedical model.

With recent advances in molecular genetics, more than a few believe that human ills (including health problems) are located in the genes and the molecules coded by them. For those who so believe, issues like the environment, society, and other blah-blah-blahs are merely ideological elements that feed the political action of a handful of upstarts, or in a more useful way, when properly presented, to serve as an enticing introduction to the discourse of even the very proponents of the biomedical model. This reminds us of Pasteur's Revolution, a transcendental moment in the progress of scientific knowledge; however, when it was contextualized within the philosophical hue of Positivism it transmuted the idea of microbial causality of disease (a huge step forward in late 19th-century scientific knowledge) into dogma, a fact with repercussions that are still felt today and that have hampered (if not completely impeded) other approaches to health and human diseases. An analysis of recent advances in biology and molecular genetics shows how these fields have spawned a new revolution in knowledge of the human body, but that they have simultaneously fed a growing legion of ideas that once again seek to reduce human health to its biological determinants, considering discussions of man and the environment or man and society as merely ideological, with no scientific basis.

The paper currently under debate touches on these and other discussions and proposes a model, the "ecosystem approach", which is certainly appealing since it "brings together the socioeconomic and biophysical approach to health". Obviously, if the biomedical model currently predominates when the issue is knowledge concerning the causes of health and diseases, what can we expect from the interventions to be conducted vis-à-vis supposedly 
known problems? A question that remains to be answered is whether we can propose effective and scientifically sound interventions without a clear causal model for health problems. Elementary scientific logic tells us that when we intervene in reality we must avail ourselves of reasonable models on which to test the intervention, but that each intervention also needs to be empirically tested. Herein lies an imperfection left by incomplete scientific progress, that is, the scarcity of resources for evaluation of interventions. If we now sometimes spend decades discussing whether a given vaccine is effective, we can only imagine tackling the daunting task of evaluating a complex and much less clearly outlined intervention as proposed under the "ecosystem approach".

Of course the ideas laid out here may suggest a paralyzing and backward-thinking type of "scientism", as opposed to the "progressivism" of the "ecosystem approach". No, I would never think that actions should necessarily be governed from beginning to end by scientific rationality, as indeed is the status that the "ecosystem approach" seeks. However, I believe that interventions in human populations are politically defined, with a greater or lesser degree of rationality and scientific basis. There is no doubt that human health underwent interventions before scientific knowledge existed, and sometimes even with great success.

In short, I do not believe that we have "scientific" answers to many of the main issues affecting human health. We know that many things are wrong, we share in the criticism contained in the paper, and we agree with the urgent need to "address the flaws in reasoning and tactics we have employed to date". However, all this serves more to orient the agenda for a scientific program and less to orient scientifically based interventions. Meanwhile, there is a wide range of evidence suggesting that changes are needed in society and the environment to achieve better health standards, but that this agenda is far from being defined in merely scientific terms. At most, the sciences in their current stage can provide clues for politically organized societies to choose the best actions, or sometimes the lesser of two evils, with a view towards solving their health problems. It was no coincidence that the report by an expert committee named by the UK Ministry of Health to recommend policies for reducing existing health inequalities noted that interventions in this field had rarely been submitted to controlled evaluation methods; however, this did not keep the committee from seeking its own alternatives in order to issue opinions on the effectiveness of existing health interventions and thus offer scientifically based alternatives to bolster the country's social health policies (Acheson et al., 1998). Some believe that epidemiology's multifactorial causal models only serve as a counterpoint to traditional biomedical models when they are based on the idea that health (as a biologically based event) is, in the final analysis, a social phenomenon (Tesh, 1998) and that in order to be effective, proposals generated from the perspective of social epidemiology must seek not only scientific support but above all social and political backing (Heymann, 2000).

ACHESON, D.; BARKER, D.; CHAMBERS, J.; GRAHAM, H.; MARMOT, M. \& WHITEHEAD, M., 1998. Independent Inquiry into Health Inequalities. London: The Stationery Office.

BARRETO, M. L., 1998. Por uma epidemiologia de saúde coletiva. Revista Brasileira de Epidemiologia, 1:104-130.

EHIRI, J. E. \& PROWSE, J. M., 1999. Child health promotion in developing countries: The case for integration of environmental and social interventions? Health Policy and Planning, 14:1-10.

HEYMANN, S. J., 2000. Health and social policy. In: Social Epidemiology (L. F. Berkman \& J. Kawachi, eds.), pp. 368-382, New York: Oxford University Press.

TESH, S. N., 1988. Hidden Arguments: Political Ideology and Disease Prevention Policy. New Brunswick: Rutgers University Press. 
The author replies

O autor responde

David WaltnerToews
I am grateful to the respondents for their critiques both of the arguments I have made, and of the less-than-clear way in which I presented them. They have been generous in making allowances for my own struggle with understanding and presenting the theory and the practice of an ecosystem approach to health. I have tried to incorporate the editorial comments into the article itself in such a way as to clarify my arguments but not, in the interests of real debate, to change them.

I feel the need to clarify the context of the article and make a few general comments. I was invited to take the ecosystem approach to health and apply it to how we think about tropical and emerging diseases. I have elsewhere discussed concepts and models of health in some detail, and in this article focused only on the tension between health - which I describe as a negotiated construct within biophysical constraints - and disease, which is merely one of many constraints (Waltner-Toews \& Wall, 1997; Waltner-Toews, 2000). Secondly, the ecosystem approach to health, which is a participatory research and management methodology, firmly rooted in complex systems theories (which include elements of chaos and catastrophe theory), needs to be distinguished from ecosystem health, which is an attempt to apply health management ideas to ecosystems. Whereas the ecosystem approach states that "there is not one material system to which our definitions must conform”, ecosystem health tends to take a more biomedical view that there is indeed one material system on which we can agree, and whose health we can assess. Thus ecosystem health tends to focus on outcomes, and the ecosystem approach tends to focus on process. This is obviously not a clear division, rather a difference of focus.

Luiz Jacintho da Silva is quite correct in citing the historical antecedents of viewing diseases in ecological context. What distinguishes Hippocrates, the 19th-century sanitarians, Pavlovsky, and Virchow from this current effort is a changed understanding of the natural world and our place in it. We have gone from a purely empirical sense of inter-relatedness, to miasma theories, to a focus on specific etiolog- ic agents, back to the agent-host-environment triad, and now to a more complex and sophisticated understanding of inter-relatedness. From both da Silva's and Foller's comments, it is clear that I have not communicated with sufficient clarity that the ecosystem approach, because it requires local participation to define the elements and relationships of interest in a given ecosystem, is necessarily rooted in culture as well as nature. However, as Cristina de Albuquerque Possas points out, there are tensions between the scientific tendency to homogenize, and the cultural tendency to particularize. The ecosystem approach, drawing on what has been called Post Normal Science (Funtowicz \& Ravetz, 1994), incorporates these tensions by requiring negotiation and what James Kay has called "cross talk" (Kay et al., 1999). Because of this, implementing "ecosystem approach to health" programs must face not only deficits in our understanding of socioecological systems, but very real and often daunting political power struggles. We continue to debate these issues, and how to deal with them, in workshops sponsored by the Network for Ecosystem Sustainability and Health (NESH), as well as on our web-site (www.nesh.ca).

Given the practical issues of competing interests, governance, and uncertainties not just among disciplines, but among researchers and non-researchers, both Foller and Moran wonder about implementing this approach. They are quite correct to see these as challenges, but I think Moran is unduly pessimistic. Conflict resolution in the development context has received considerable attention in recent years (see, for instance, Buckles, 1999). Furthermore, we have found, at least at the local community level, that many people understand, accept, and can work with uncertainty and compromise if they are part of the investigative and management process. Many government institutions have problems implementing policies on public health and environmental issues because they assume that their "experts" can adequately define the risks and hence impose solutions on the public. The public will shoulder risks they have chosen, but not those imposed. In this context, the major practical constraints to implementing this approach relate to democracy, a sense of a common good beyond the individual household, and knowledge (not necessarily formal education, but the ability to articulate understanding and argument). In many poor countries, the third component is missing. In North America, a lack of the second component has proven to be the major problem. Again, there are exceptions; some of us 
have found modern students of science in North America to be unable to clearly articulate understandings and arguments. I did not discuss specific methodological tools in the article, but the process invariably involves triangulating results from a combination of methods, ranging from those developed by participatory action practitioners (which are usually central), to those used in conventional scholarly inquiry, Soft Systems Methodology (Checkland \& Scholes, 1991), influence diagrams, and newer dynamic simulation models and Geographic Information Systems. The specific tools used are determined by the questions being asked by the participants.

José Maria G. de Almeida Jr. raises several interesting and important points. Since my wife is a counselor-therapist, I am well aware of EMDR (which links mind and body at an individual level), as well as the broader literature linking mental and social conditions to biophysical health at more encompassing systemic levels in the socio-ecological holarchies (e.g. Evans et al., 1994). Health in the tropics has both socioeconomic (e.g., poverty) and ecological (e.g., climate) constraints. One of the ways we have dealt with that in implementing the ecosystem approach is to require local, public participation defining the research questions and the management options. The process itself empowers people and promotes health; this is what I mean by saying that the means achieve the ends.

I consider gene therapy to be a medical procedure and not a health promotion technique, and cloning faces the same problems as other genetic engineering of organisms, in that (among other things) it changes the rate of change at a particular scale (the individual) and hence creates serious disturbances at other, co-evolving scales which cannot adapt as quickly (Giampietro, 1994). Bill Reese makes this point much more forcefully in his comments. If I have downplayed the rapidity of change and the potential for catastrophe it is because, from a practical point of view, I have found that such descriptions of the situation, while probably true, tend to foster some combination of panic with despair, numbness, or totalitarianism. Indeed, I would argue that many of the lists of quantitative indicators of sustainability generated by international agencies reflect these tendencies. Faced with the urgency of systemic breakdown and hemorrhaging of species, my veterinary training tells me that calm, considered interventions may get us further toward our goals.

Still, Dubos' "mirage of health" can be discouraging for anyone working in the health field, since it quite clearly demonstrates that health, as a state, is a moving, probably unattainable, target. Studies using the ecosystem approach may be classified in static form (Figure 1), and portions of it may be teased apart and made to appear linear (Figure 2), but the process overall is always, in practice, an iterative one of continuous re-negotiation of goals defined from different perspectives, actions, assessments, changed understandings, and renegotiation (Figure 3 ). This is not a process with a beginning and an end, and reflects the fact that good health is a function of both the outcomes and how they are achieved. Health in this context is not so much a mirage as a sense of well-being that we need to continually redefine and renew as the world changes.

Dr. Lima Barreto's comments raise the question of whether the ecosystem approach, as here defined, is science at all. John Robinson, Director of the Sustainable Development Research Institute at the University of British Columbia, has argued that what we are talking about is "co-generation of knowledge", and that by referring to it as a kind of "post-normal science" we are giving unwarranted credit to scientists (personal communication). People like Funtowicz and Ravetz tend to see this as an enrichment or expansion in the nature of science, in which the primary task of scientists is to help us find ways to live with what appears to be irreducible uncertainty. That is, in addressing questions marked by epistemological and ethical conflicts and where the stakes and uncertainties are high, a new kind of public science, responding to an expanded peer group, is required. This is still, I think they would argue, a systematic gathering of knowledge in the pursuit of general laws, open to scrutiny and evaluation and verification by peers, and thus qualifies as a kind of science. One could argue that this is simply a sort of "rational politics", a politics informed by science. Barreto's response to this is that political interventions are only partly rational and scientific. As, I would add, is the very notion of health. Indeed, one member of our NESH group - not coincidentally, I think, a Peruvian - has argued that we pay far too little attention to the forces of political economy in our ecosystem approach. Surveying the political and health landscape at the beginning of the 21 st century, I have no convincing response to this. The struggle to find reasonable resolutions to complex and often tragically absurd situations is a struggle, I think, worth pursuing.

Barreto wonders how we can measure success. The ecosystem approach is focused on re- 
solving the practical, complex problems of how we can live well (with health), as one species among many, on this planet. In a constantly changing context, how can we know if we have succeeded? In at least one of our projects (in Kenya) we derived two sets of indicators for measuring success - one created by the research team, and one created primarily by the villagers. The latter, we found, were the more useful - though much more difficult for researchers to measure - because they reflected the qualities of life that people actually cared about. Nevertheless, health is also a concept full of contradictions, in which for instance, global health may dictate restrictions on local health, and population health in a context of ecological constraints requires the death of some individuals. Indeed, we face many tragedies which have no technical solutions. As both a scientist and an activist, I think that the ecosystem approach to health, as defined in this paper, which struggles as much with process as with outcome, offers (at least to the extent to which the ideal is realized) some hope for dealing with questions where conventional science and politics appear to be at an impasse. Nevertheless, I do not believe that we will ever find a definitive way of coping with the uncertainty, tragedy, and wonder of the human condition. For this reason, music, poetry, stories, and rituals will always be essential for achieving health. But that is another paper.

BUCKLES, D., 1999. Conflict and Collaboration in Natural Resource Management. Ottawa/Washington, D.C.: IDRC/World Bank Institute.

See the original article for all other references. 